\title{
Telehealth Interventions for Family Caregivers of Persons with Chronic Health Conditions: A Systematic Review of Randomized Controlled Trials
}

\author{
Lucinda J. Graven $\mathbb{D}^{1},{ }^{1}$ Robert L. Glueckauf $\mathbb{D}^{2},{ }^{2}$ Rachel A. Regal $\mathbb{D},{ }^{3}$ Nancy K. Merbitz $\mathbb{D},{ }^{4}$ \\ Mia L. A. Lustria $\mathbb{D}^{5}{ }^{5}$ and Brittny A. James $\mathbb{1}^{6}$ \\ ${ }^{1}$ Florida State University College of Nursing, Tallahassee, FL, USA \\ ${ }^{2}$ Florida State University College of Medicine, Tallahassee, FL, USA \\ ${ }^{3}$ Virginia Commonwealth University, Richmond, VA, USA \\ ${ }^{4}$ Louis Stokes Cleveland Veterans Administration Medical Center, Cleveland, OH, USA \\ ${ }^{5}$ Florida State University College of Communication and Information, Tallahassee, FL, USA \\ ${ }^{6}$ Georgia Gwinnett College, Lawrenceville, GA, USA
}

Correspondence should be addressed to Lucinda J. Graven; lgraven@fsu.edu

Received 17 January 2020; Revised 23 April 2021; Accepted 11 May 2021; Published 22 May 2021

Academic Editor: Fei Hu

Copyright (c) 2021 Lucinda J. Graven et al. This is an open access article distributed under the Creative Commons Attribution License, which permits unrestricted use, distribution, and reproduction in any medium, provided the original work is properly cited.

\begin{abstract}
Objective. The purpose of this study was to provide an in-depth analysis of the components and outcomes of telehealth interventions for family caregivers of individuals with chronic health conditions. Methods. A systematic review of 17 databases was conducted for randomized controlled trials published between January 2002 and January 2017. Interventions were analyzed based on type of telecommunication modality, caregiver and care recipient characteristics, intervention components, and caregiver outcomes. Results. A total of 57 articles met criteria for inclusion. Telephone was the most frequently used mode of telehealth delivery and focused primarily on caregivers of older adults with dementia and stroke. Skills training was the most prevalent treatment strategy across telephone, web, and combined telephone and web modalities. Improved psychological functioning was reported most frequently across telehealth modalities. Conclusion. Telehealth is an effective tool in delivering caregiver interventions and leads to significant improvement in caregiver outcomes. Telephone was used most often to deliver cognitive-behavioral and psychoeducational strategies as compared to web and combined telephone and web modalities. Further research is needed to examine the effects of telehealth interventions on caregiving skills and self-efficacy, as well as health outcomes.
\end{abstract}

\section{Introduction}

Approximately 44 million family members and significant others residing in the United States provide unpaid assistive care to children and adults with chronic health conditions [1]. The responsibilities of family caregivers vary considerably depending on the age of the care recipient, severity of the disability, and availability of resources [2]. As a consequence of caregiving activities (e.g., providing assistance with bathing and managing medications) and other responsibilities (e.g., work commitments), caregivers must perform a difficult balancing act. It is commonplace for family caregivers to prioritize the needs of their loved ones with chronic illnesses above their own personal concerns and lifestyle preferences. Although they often verbalize the importance of health-promoting activities, many caregivers find it challenging to create time for self-care opportunities, to attend doctors' appointments, and to ask for caregiving assistance from other family members [3, 4]. Caregivers often report substantial declines in social activities, disrupted familial relationships, financial problems, and deterioration in physical and mental health [5].

In an effort to mitigate these difficulties, governmental and healthcare organizations have called for research on the effects 
of telehealth interventions in meeting the informational, psychosocial, and healthcare needs of family caregivers. Several of these entities have emphasized the importance of ensuring ease of access, uptake of services, and cost-effectiveness [68]. Telehealth services for family caregivers facilitate access to interventions in convenient locations and in turn reduce costs of transportation and respite care. Caregivers with partor full-time employment also are able to receive needed services during off-hours, thus reducing work disruptions and potential loss of wages. Furthermore, caregivers residing in rural areas or crowded urban communities may find telehealth modalities more convenient, reducing travel costs, parking restrictions, and/or risks to self and property $[9,10]$.

Although research on the outcomes of telehealth interventions with family caregivers has been slower in evolving compared to research focusing on individuals with chronic illnesses, this trend has changed markedly over the past decade. Prior systematic reviews $[2,11]$ on telehealth intervention provided useful background information about caregiver and care recipient characteristics, types of telecommunication modalities and intervention approaches, and their overall pattern of findings. These reviews supported the effectiveness of telehealth interventions in improving the emotional and psychosocial functioning of family caregivers of persons with chronic health conditions. Although these reviews $[2,11]$ represent important initial efforts in evaluating the outcomes of caregiver telehealth interventions, a notable shortcoming limited the validity of their findings. Both reviews $[2,11]$ incorporated studies with nonexperimental research designs, ranging from case studies to quasi-experiments, thus weakening the causal conclusions that could be drawn about the efficacy of telehealth caregiver interventions.

To address this limitation, this review examined the results of randomized clinical trials assessing the effects of telehealth interventions on the psychosocial functioning, health status, and caregiving abilities of family caregivers. The decision to focus on the results of randomized controlled trials was based on prevailing standards for judging treatment efficacy [12]. Special attention also was given to the types of telecommunication modalities deployed in delivering caregiver telehealth interventions, user applications and options incorporated during the course of treatment, and their relationship to caregiver outcomes.

\section{Methods}

2.1. Identification of Studies. A literature search was performed to identify studies examining the efficacy of randomized controlled trials of telehealth interventions for family caregivers of individuals with chronic conditions published in English-language peer-reviewed journals from January 2002 to January 2017. Seventeen interdisciplinary scholarly databases were searched (Table 1) using the following terms in various combinations: "caregiver," "telemedicine," "telehealth," "video," “computer," "Internet," “conference," "remote consultation," "train," "intervention," "randomized," "controlled," and "clinical trial." These keywords were selected based on their capacity to retrieve a wide range of pertinent articles and to ensure identification of new articles,
Table 1: Academic databases searched.

1. Ageline
2. AIDS and Cancer Research Abstracts
3. CINAHL
4. Cochrane Library
5. ComDisDome
6. Google Scholar
7. Gray Literature
8. Health and Safety Science Abstracts
9. MEDLINE
10. ProQuest Dissertations \& Theses Full Text: Health \& Medicine
11. PsycINFO
12. PubMed
13. Science Citation Index Expanded
14. Social Sciences Citation Index
15. Social Science Full Text
16. Social Services Abstracts
17. Web of Science

as well as those not fully indexed. Strict inclusion/exclusion criteria also were adopted to enhance the relevance of articles for study inclusion (Table 2).

The initial search yielded 1621 potentially relevant studies archived for further review. After the removal of duplicate articles $(n=280)$, the remaining articles $(n=1341)$ were screened for eligibility. Ineligible studies were excluded $(n=899)$ (e.g., not written in English, feasibility studies, quasi-experimental design, and qualitative studies). Abstracts of the remaining studies $(n=442)$ underwent further evaluation, with additional studies excluded $(n=358)$ due to failure in meeting the inclusion criteria. Next, the full texts of the remaining articles $(n=84)$ were reviewed by two independent coders to confirm eligibility, resulting in the exclusion of 27 additional articles. A total of 57 articles met all inclusion criteria and were included in this systematic review (Figure 1). Due to the heterogeneity of study populations, interventions, and outcomes examined, we opted not to pursue a formal meta-analysis of the included studies.

\subsection{Identification and Operationalization of Intervention} Characteristics. Each study was examined to identify telecommunication modalities used during treatment, caregiver and care recipient sample characteristics, outcome measures, intervention characteristics, and primary findings. Description of these key characteristics, organized by delivery modality, can be found in Tables 3-5 (telephone, web, and combination web and telephone interventions). The interventions were further inspected to classify intervention components, caregiver applications, and user control (Table 6). Caregiver intervention components consisted of group or individual skills training, psychoeducational and resource materials, self-monitoring/tracking, reminders, and group or individual counseling. Caregiver applications included the use of email, discussion forum/online chat, online journaling, text messaging, telephone calls (independent of intervention), and provision of useful links and resources. 
TABLE 2: Inclusion and exclusion criteria for article selection.

Studies included if:

(1) Were telecommunication-based randomized controlled trials which focused on at least one caregiver outcome (i.e., health behaviors, psychosocial functioning, health service utilization, and cost or clinical outcomes)

(2) Used at least one telehealth component in $50 \%$ of caregiver training sessions (e.g., service delivery over the Internet, telephone, videophone, point-to-point videoconference, and/or chat)

(3) Were primarily focused on family caregiver intervention (may also include a care recipient training component)

(4) The care recipient had a chronic medical condition (e.g., HIV/AIDs, progressive dementia, heart failure, psychiatric disabilities, and traumatic brain injury)
Studies excluded if:

(1)Were written in languages other than English

(2) Were duplicate articles

(3) Were proposals or written descriptions of intervention programs, usability studies, quasi-experiments (i.e., used control groups, but not randomized), feasibility studies, or largely qualitative studies that lacked quantitative measures of caregiver health behavior or clinical outcomes

(4) Used telehealth technologies solely to evaluate data on physical signs and symptoms of a condition, physiological indicators of health, and/or to provide emotional support

(5) Focused exclusively on improvements in caregiver's knowledge and attitudes

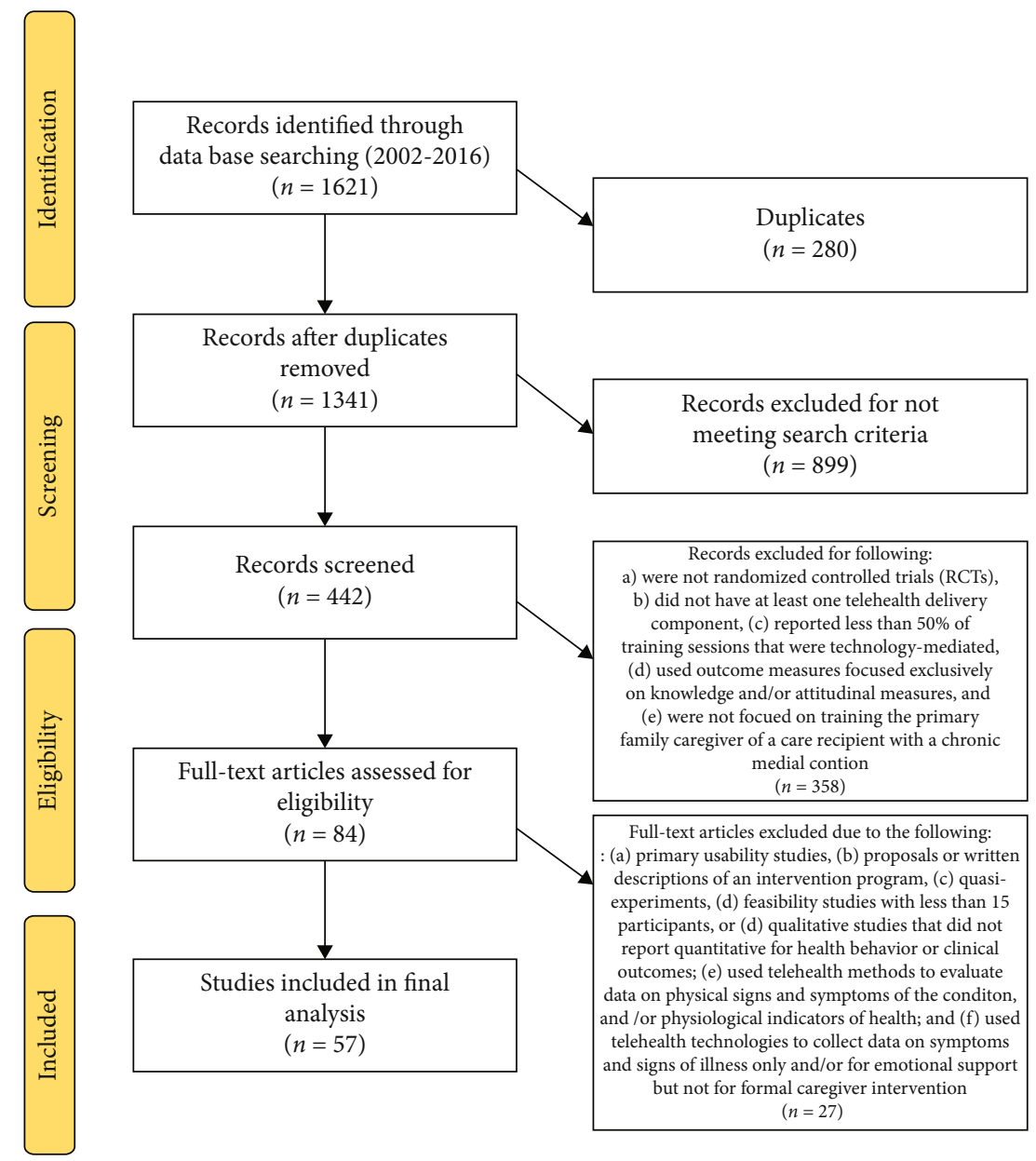

Figure 1: Prisma diagram.

Regarding user control, interventions were categorized as either facilitator-guided or self-guided. Facilitator-guided interventions used healthcare professionals to lead sessions or maintain the flow of participation during the intervention. Self-guided interventions relied exclusively on participants to complete all phases of the program.

2.3. Coding of Intervention Characteristics. Two researchers coded eligible studies independently on caregiver and care recipient demographics, intervention design, telehealth modalities utilized, methodological characteristics, and study outcomes. Operational definitions were summarized in a codebook to ensure coding procedures were performed consistently and accurately. Coder agreement was assessed on quantifiable factors across a subset of categories. Findings from both reviewers were compared, and areas of disagreement were discussed until consensus was achieved. 


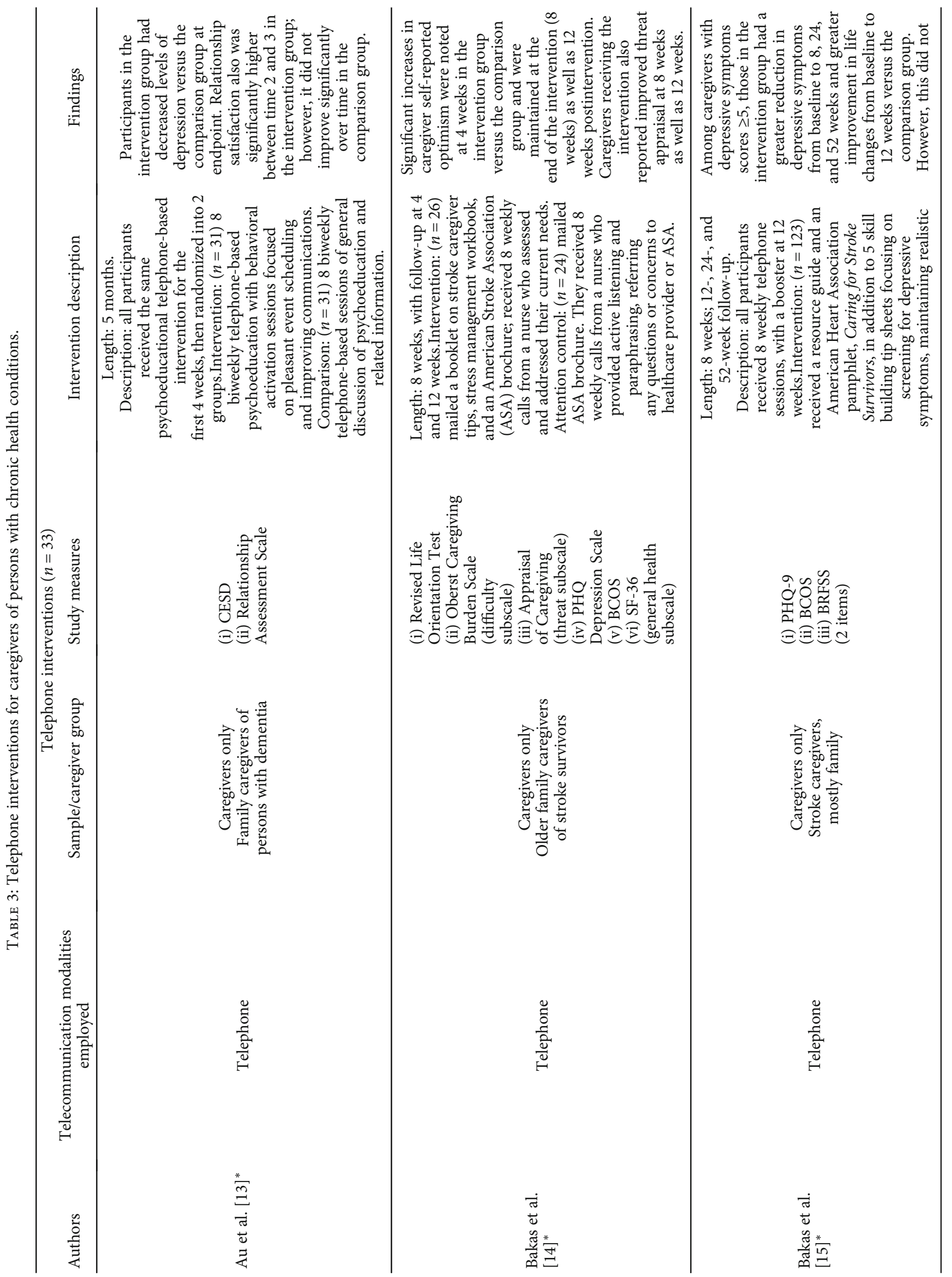




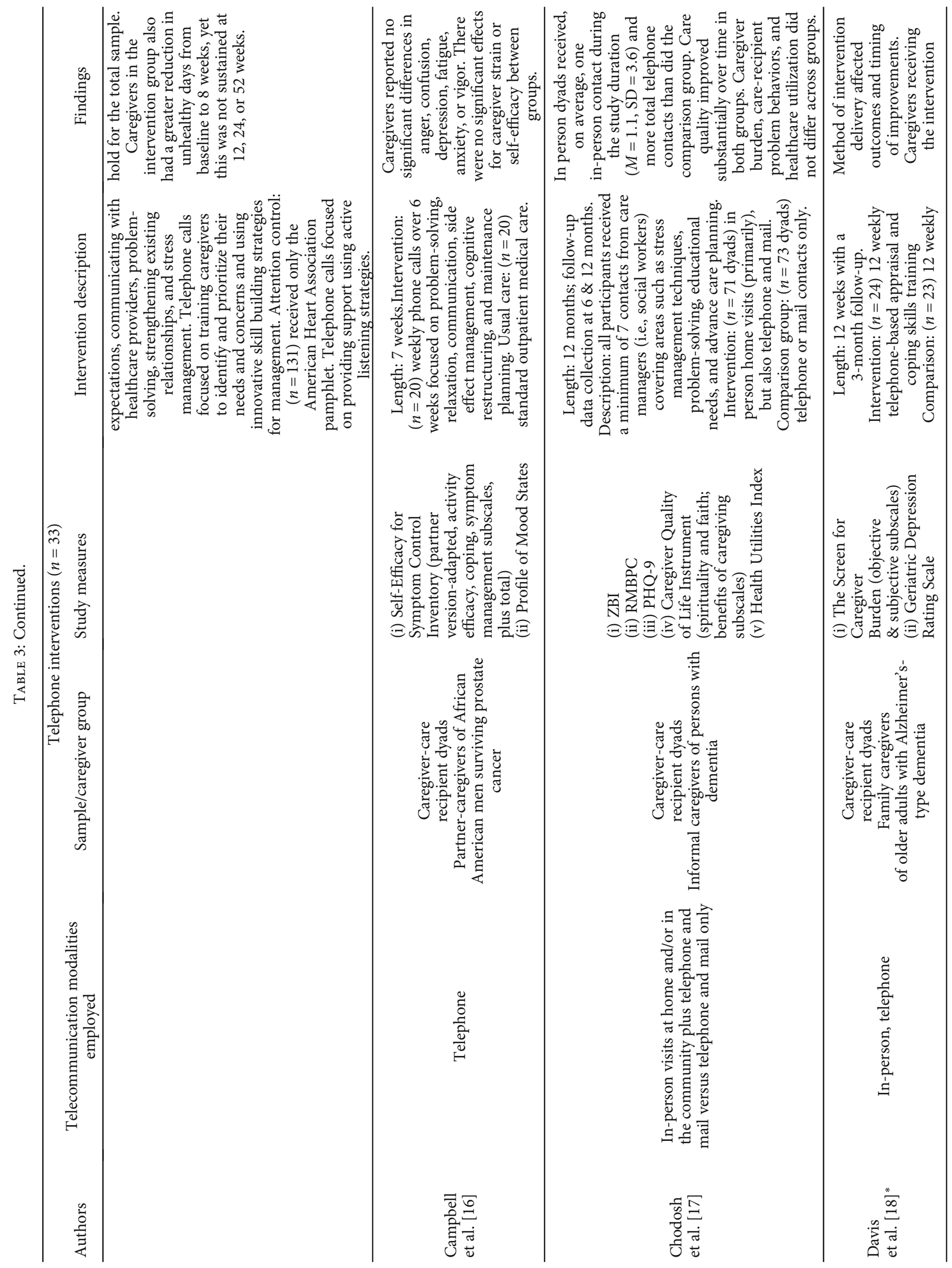




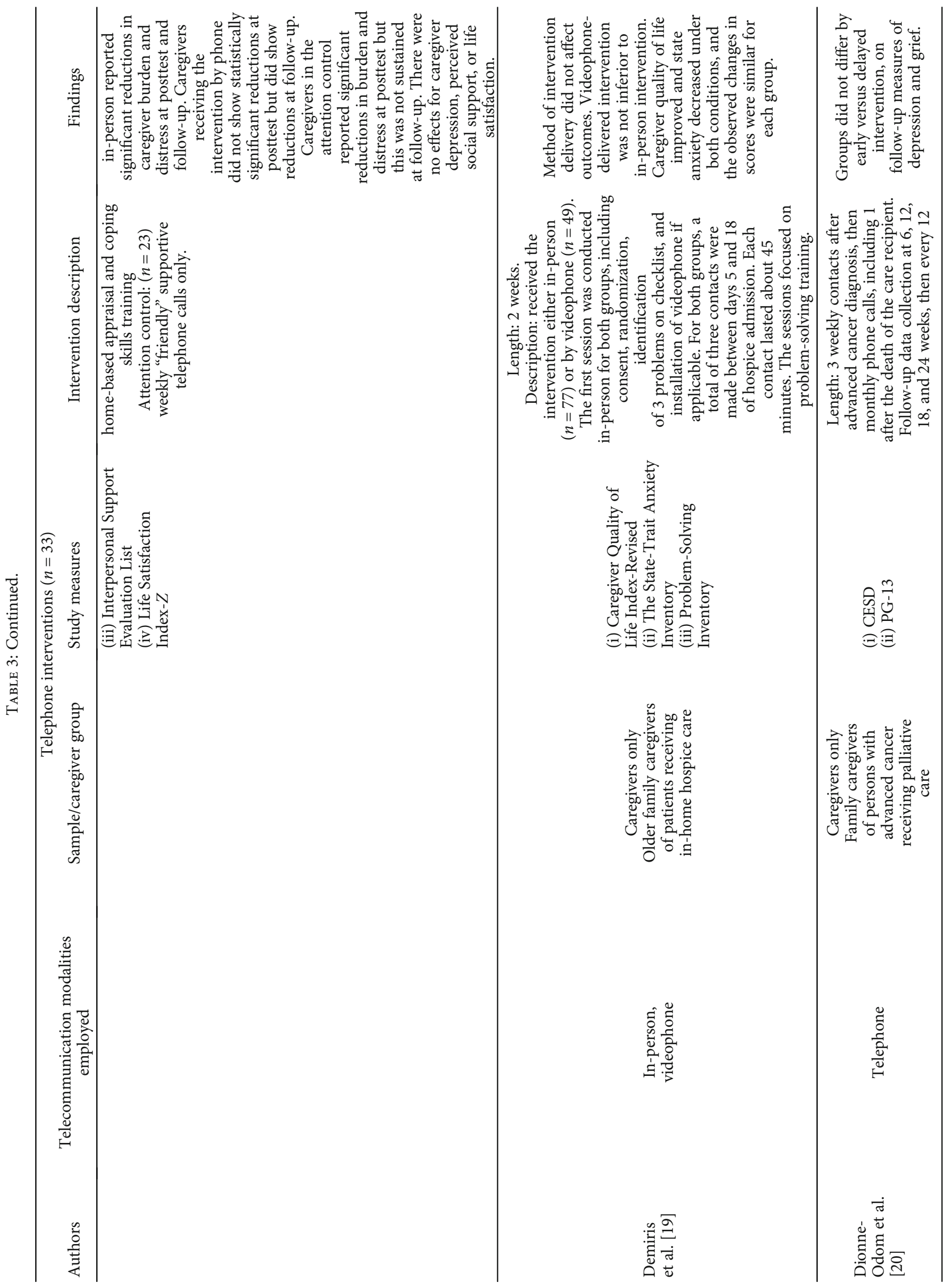




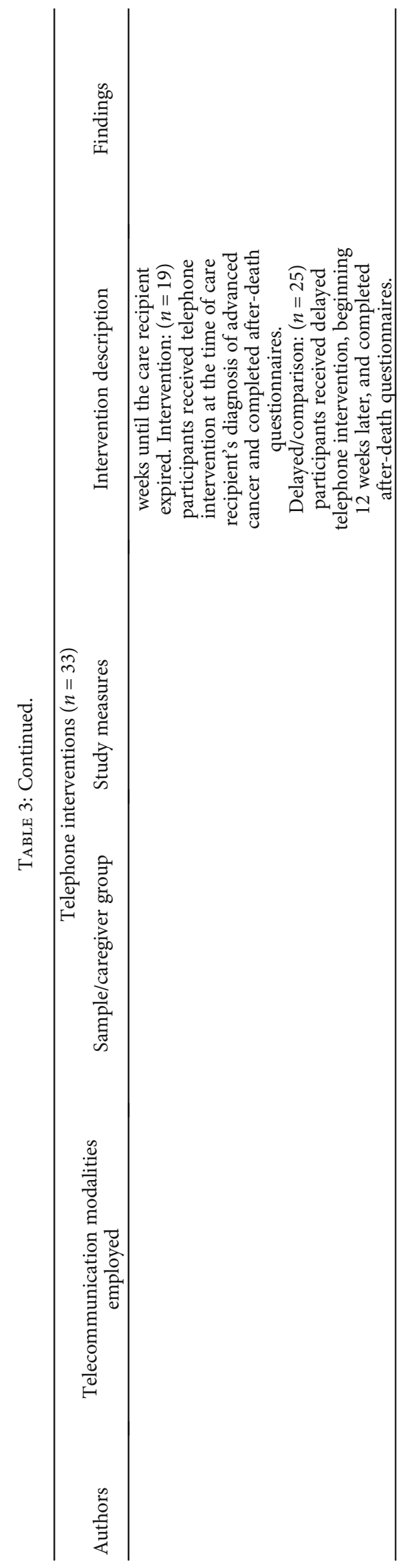

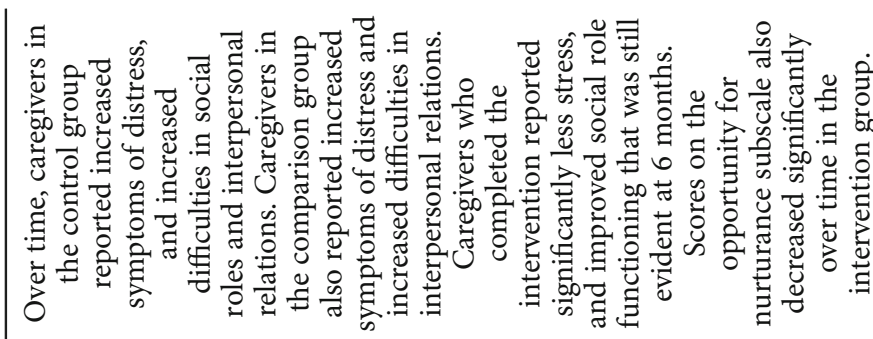
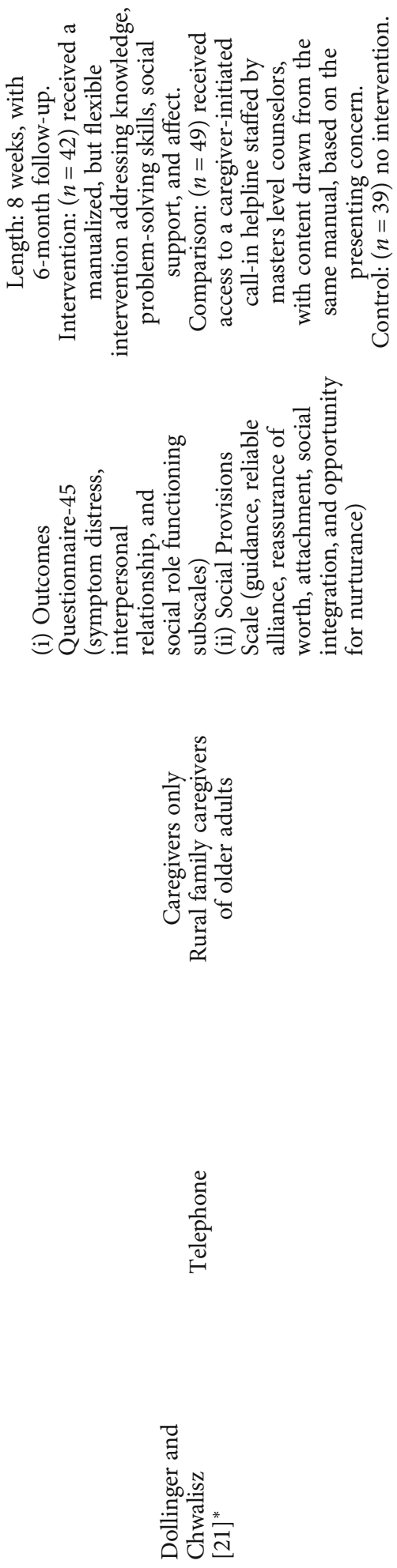

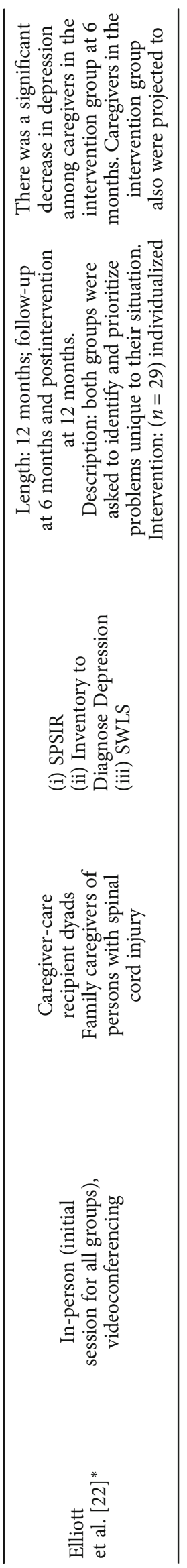




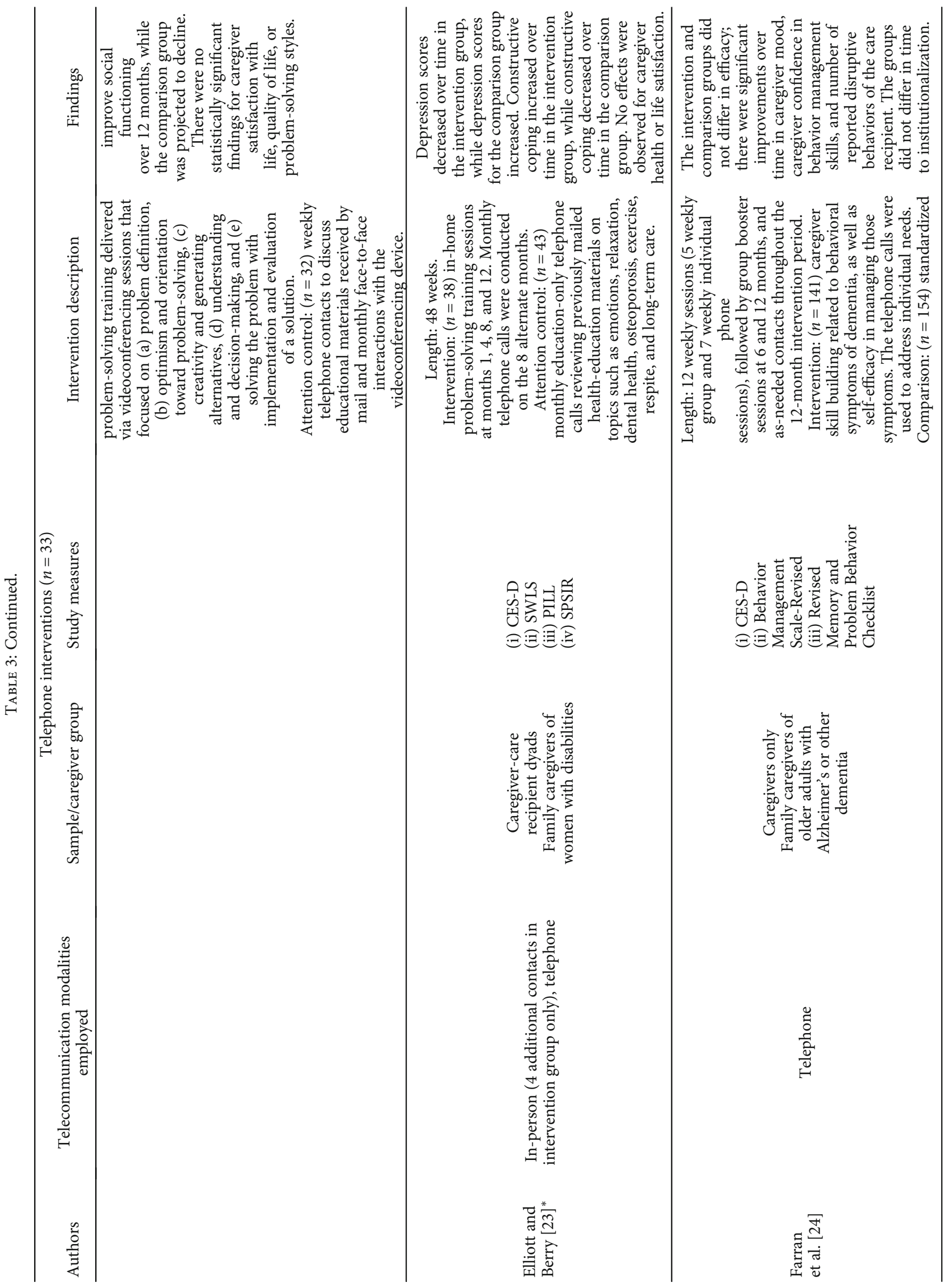




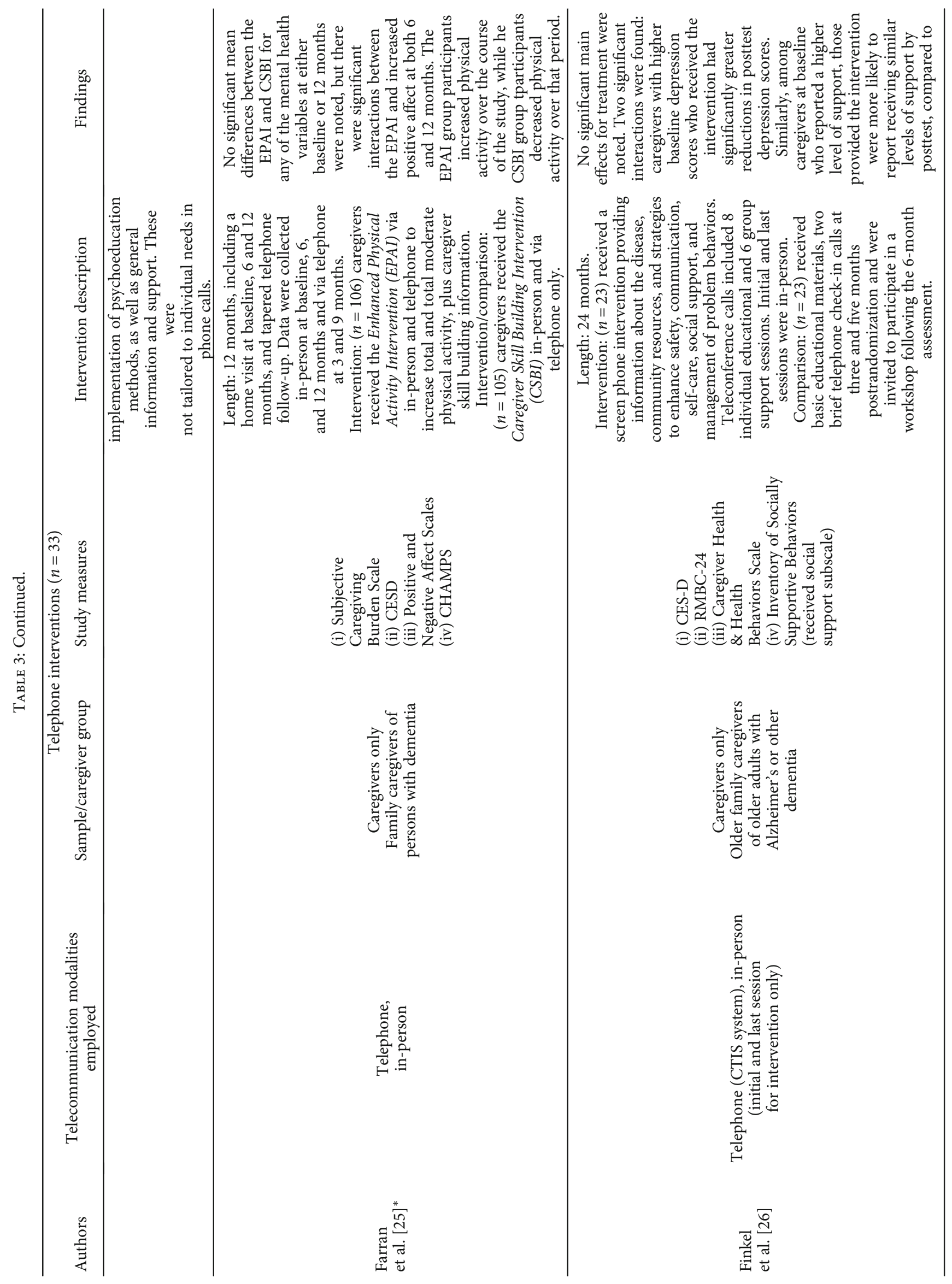




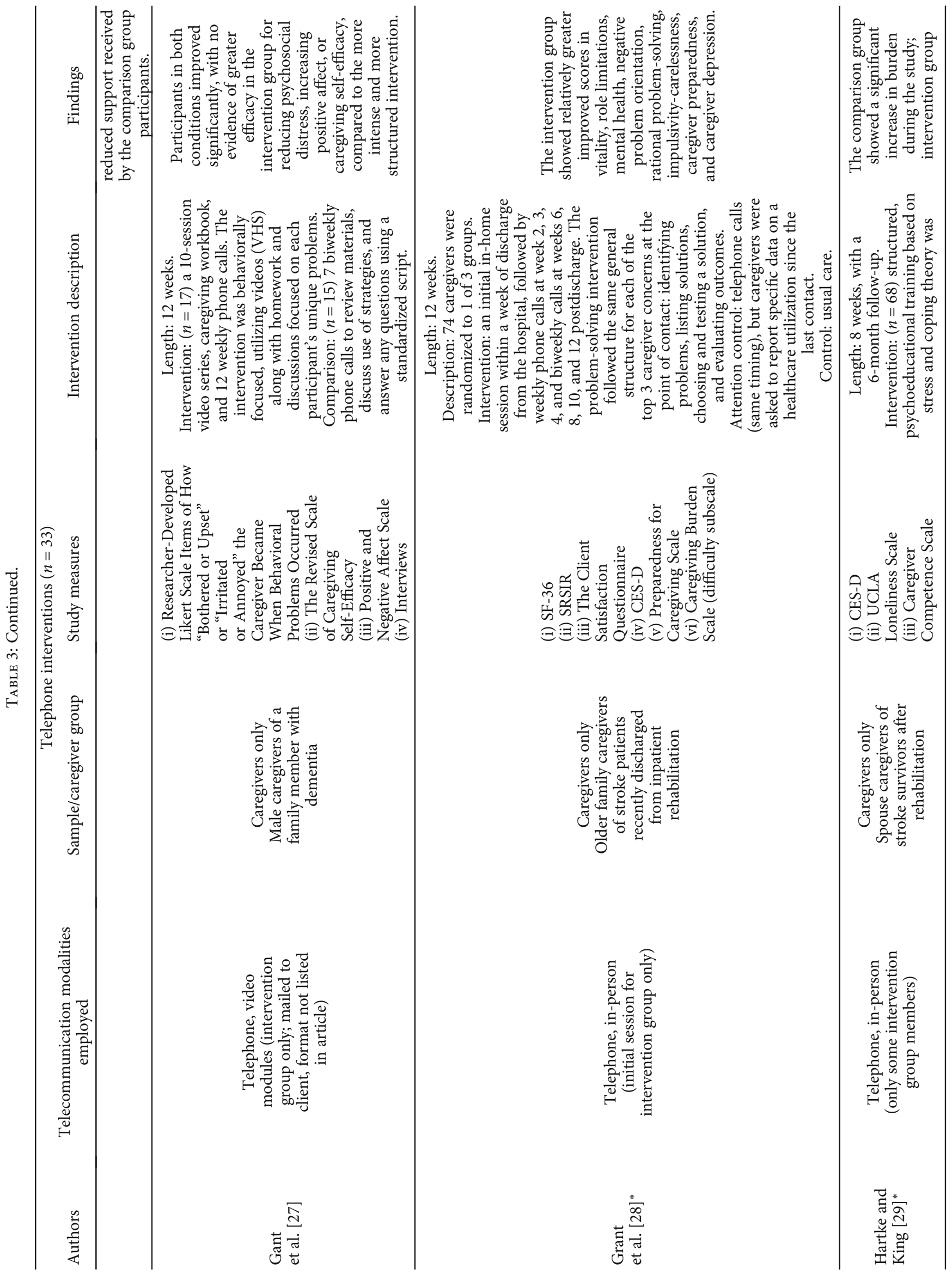




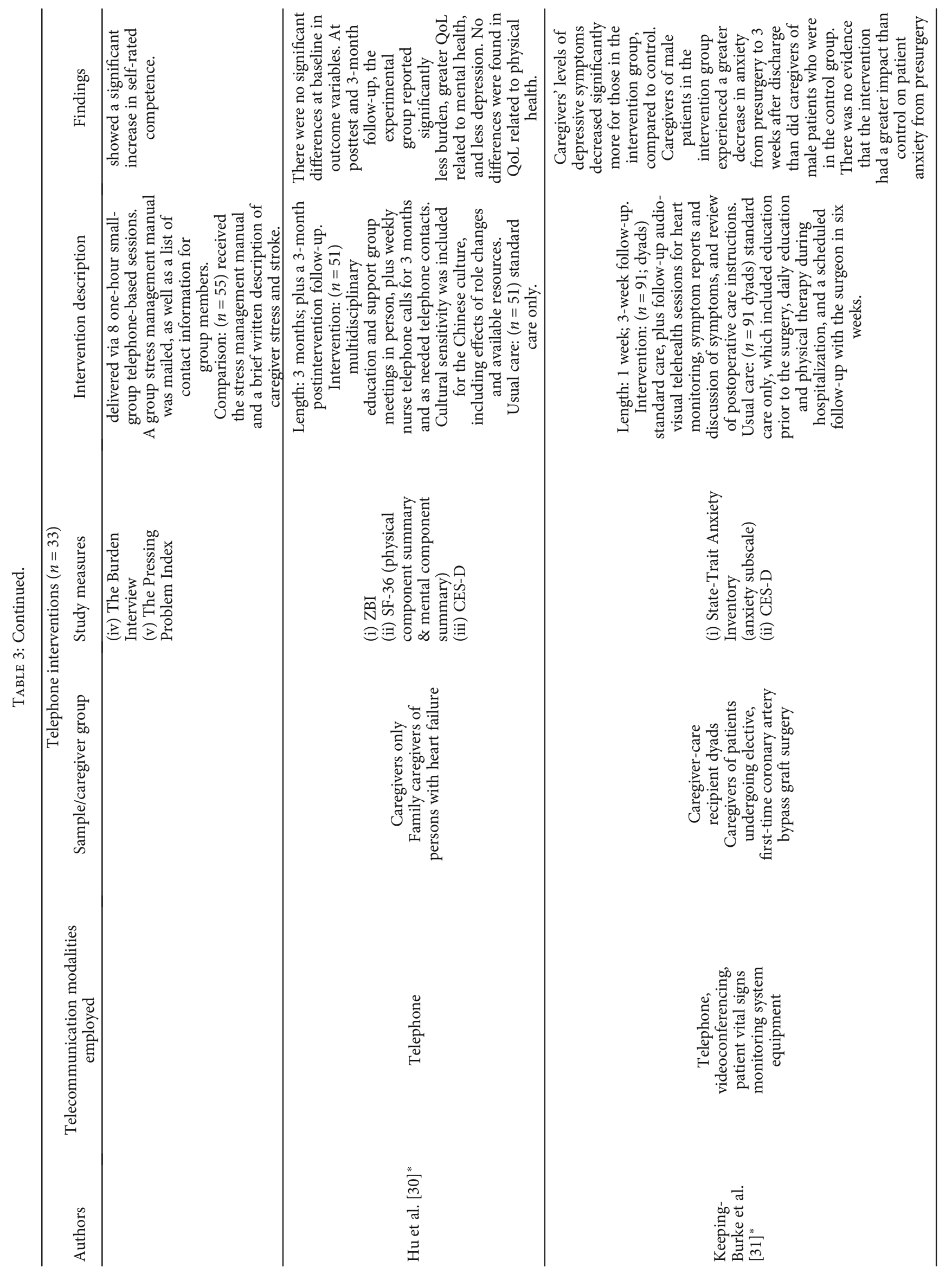




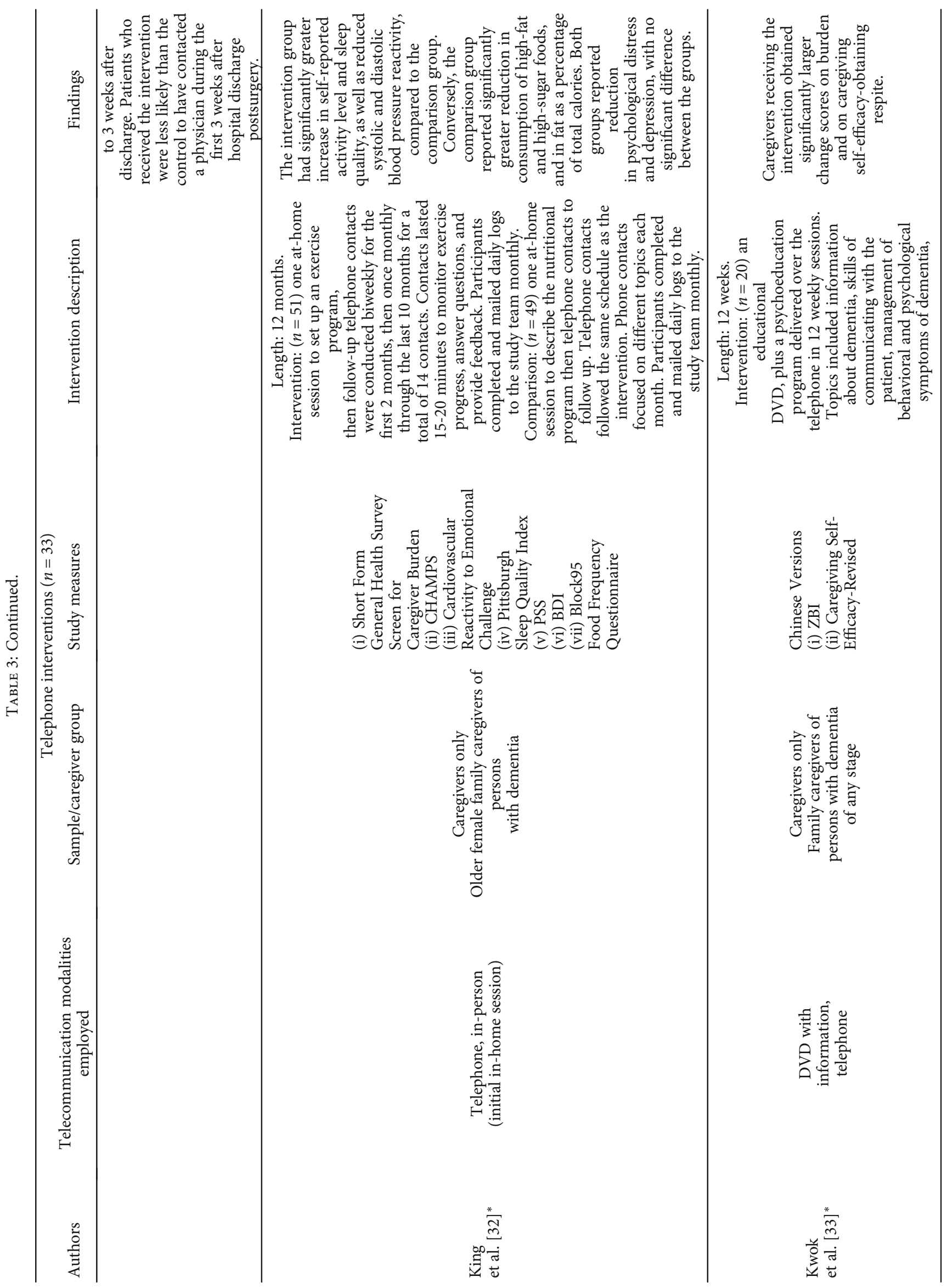




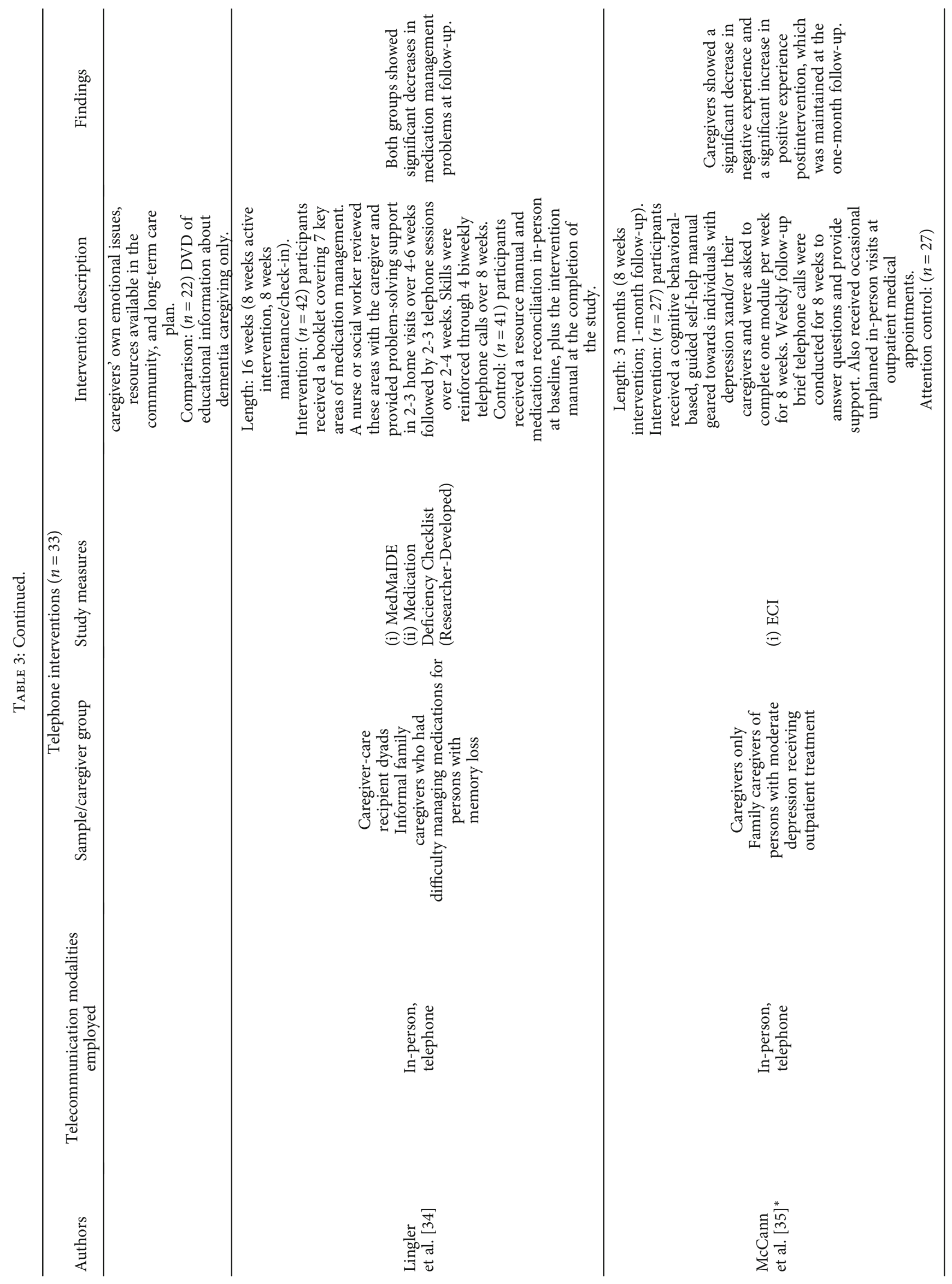




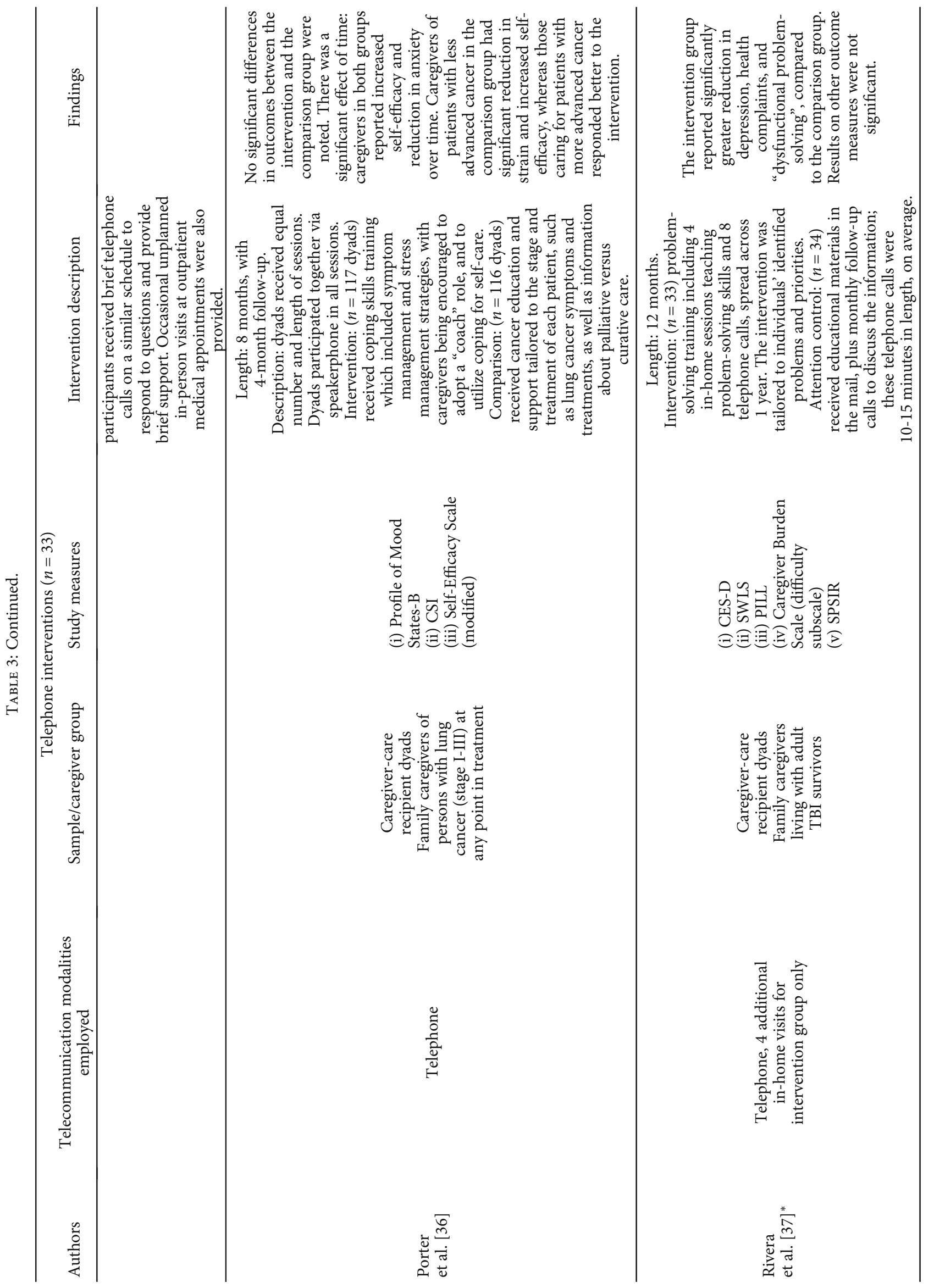




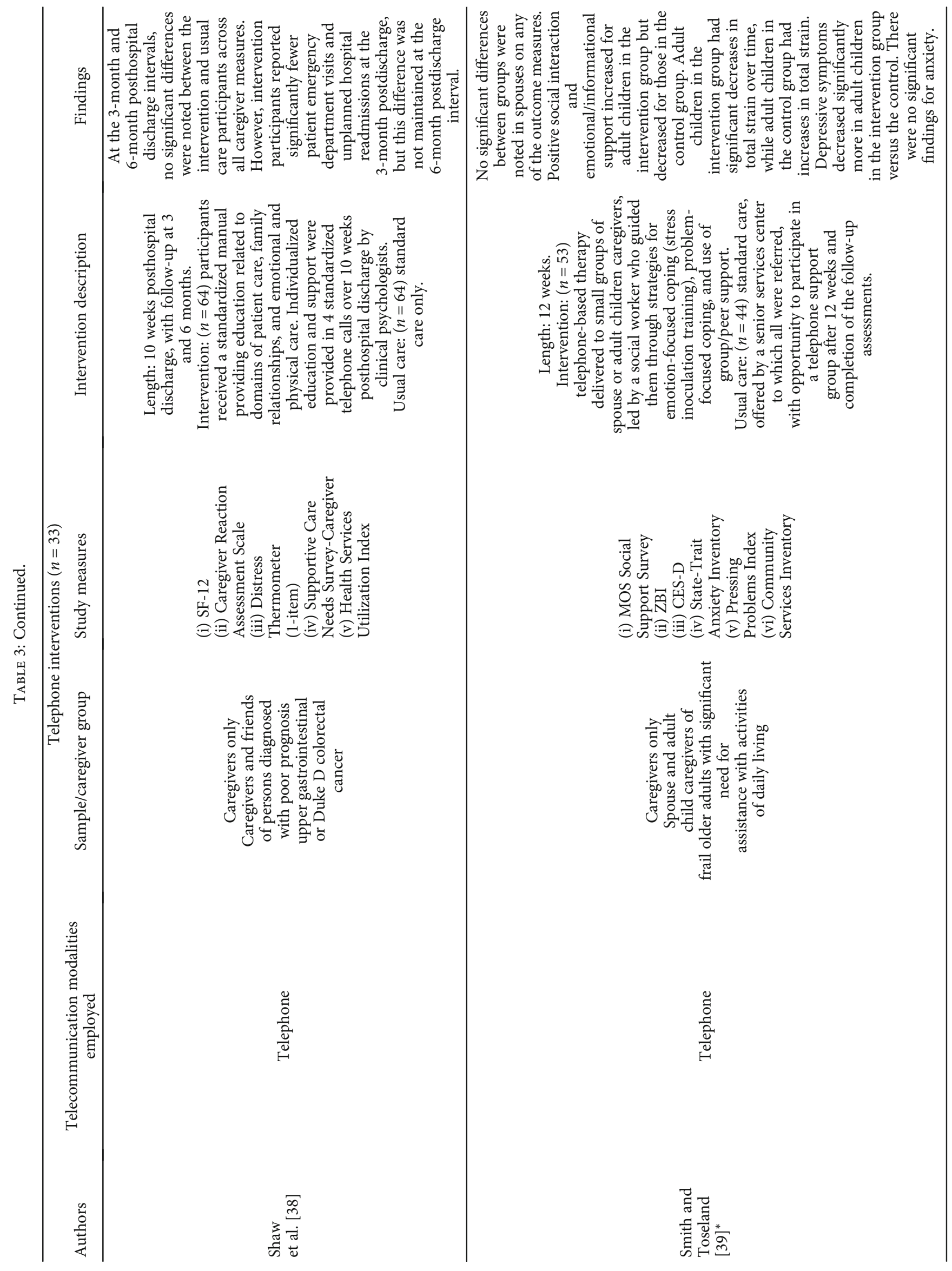




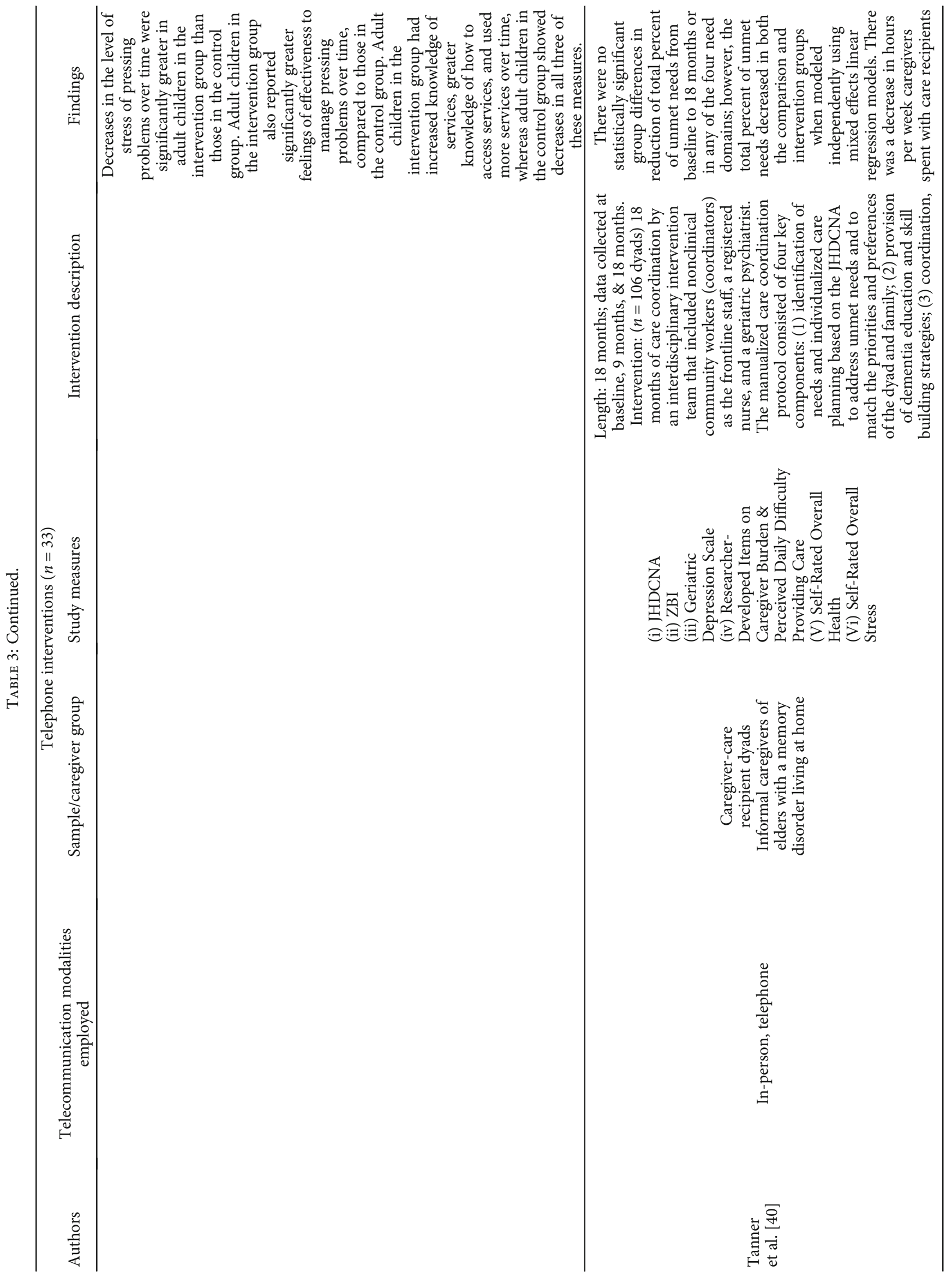




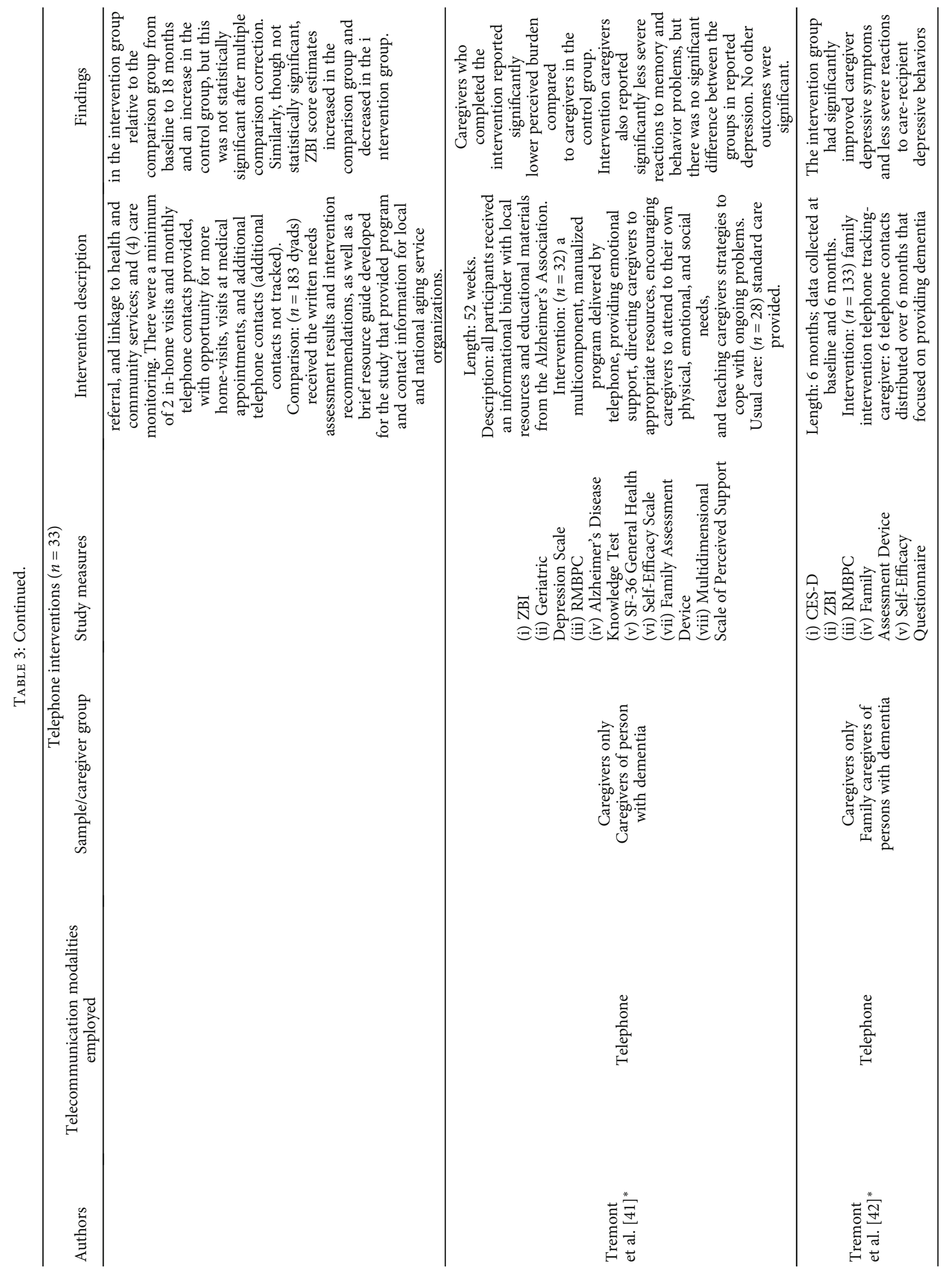




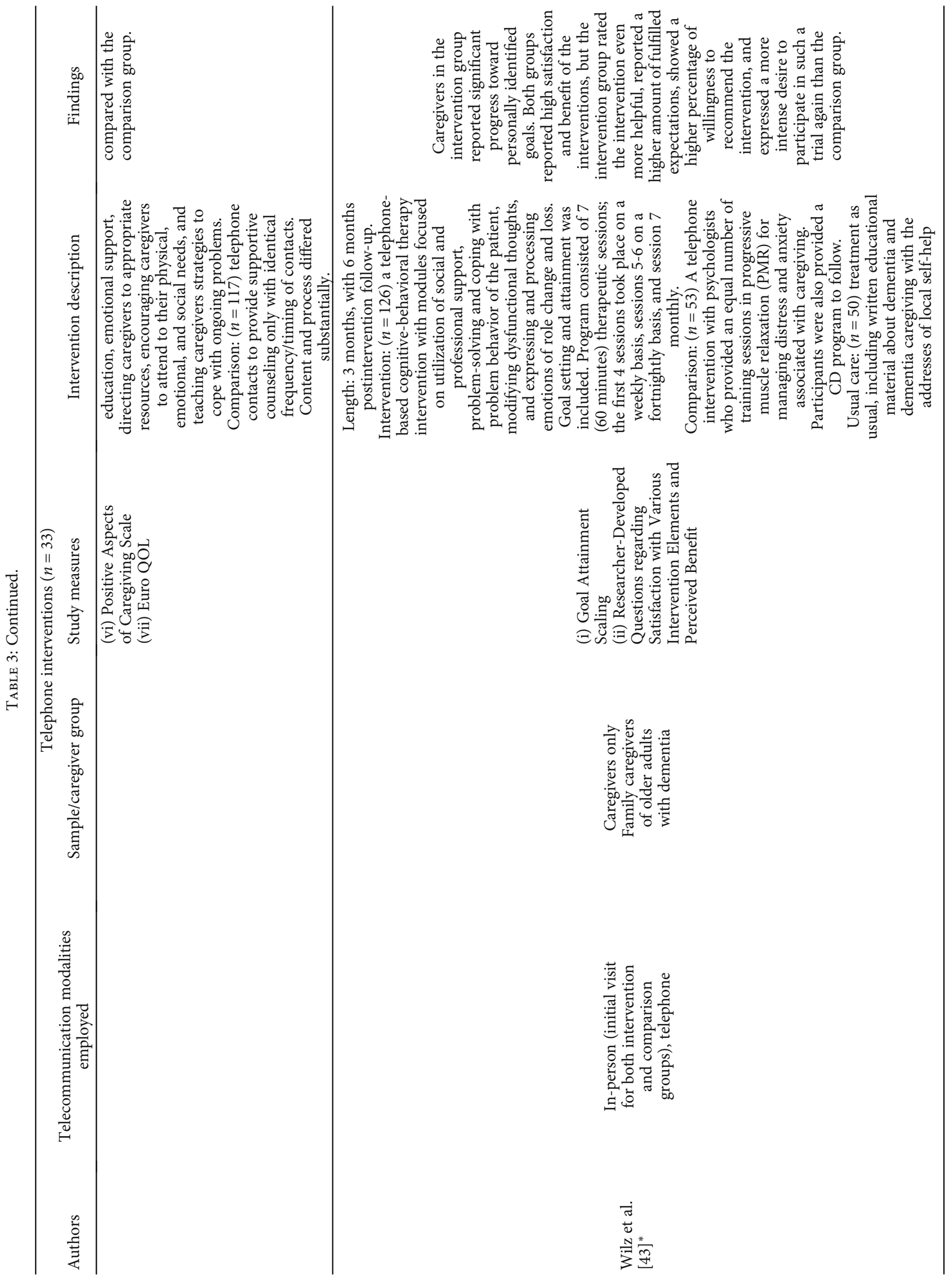




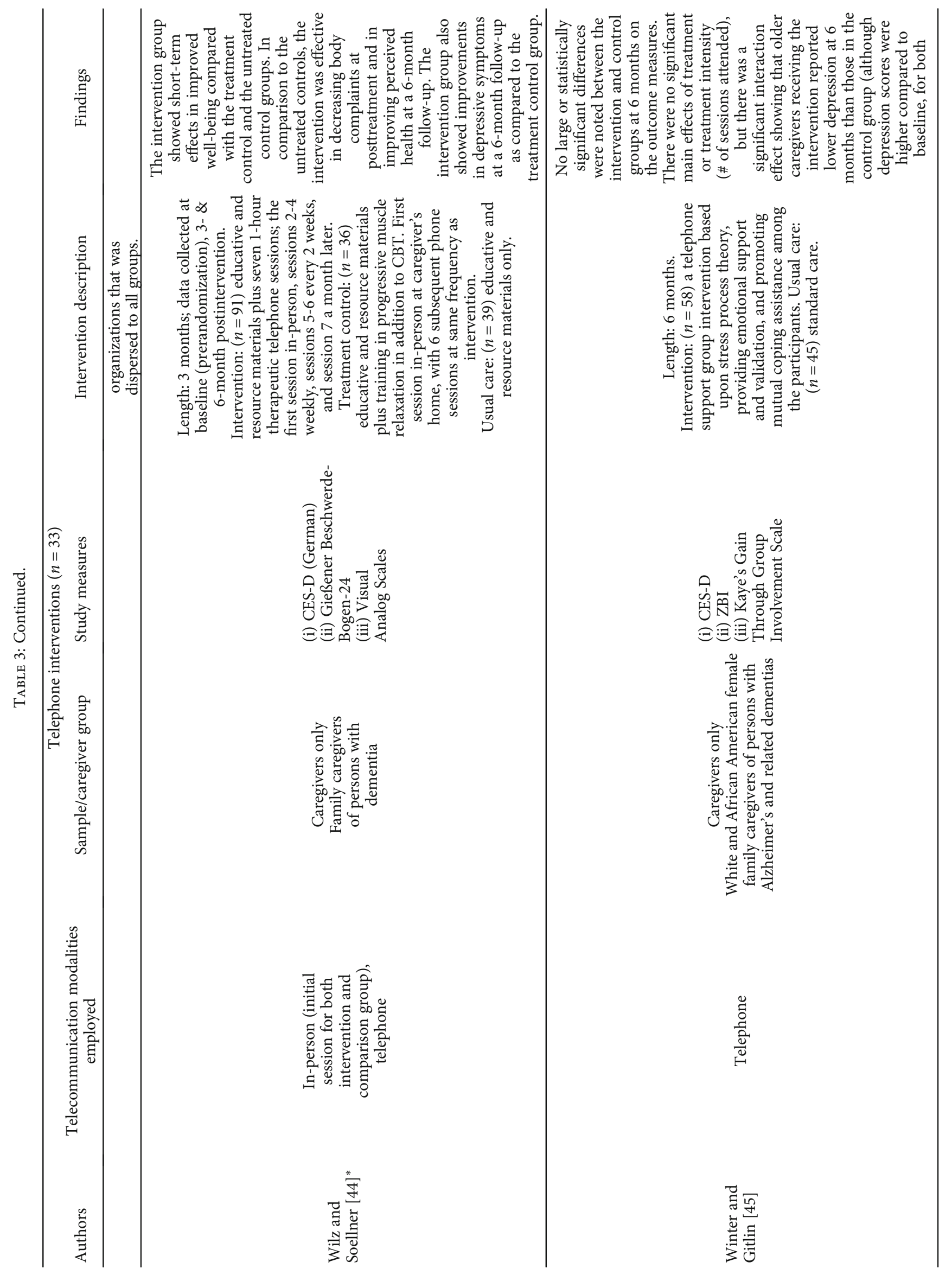




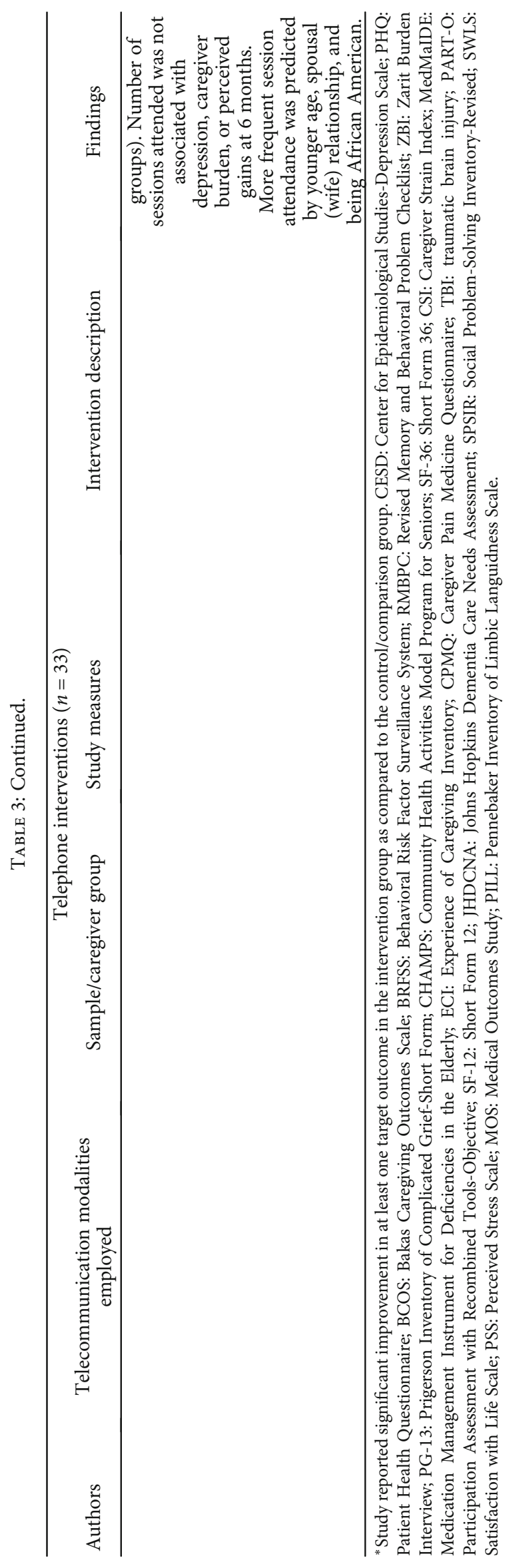


TABLE 4: Web interventions for caregivers of persons with chronic health conditions.

\begin{tabular}{|c|c|c|c|c|c|}
\hline \multicolumn{6}{|c|}{ Web interventions $(n=14)$} \\
\hline Authors & & Caregiver group & Study measures & $\begin{array}{c}\text { Intervention } \\
\text { description }\end{array}$ & Findings \\
\hline $\begin{array}{l}\text { Beauchamp } \\
\text { et al. [46]* }\end{array}$ & $\begin{array}{l}\text { Asynchronous web- } \\
\text { based modules with } \\
\text { tailoring and videos }\end{array}$ & $\begin{array}{l}\text { Caregivers only } \\
\text { Caregivers of family } \\
\text { members with } \\
\text { dementia who } \\
\text { maintained outside } \\
\text { employment }\end{array}$ & $\begin{array}{l}\text { (i) CES-D } \\
\text { (ii) State-Trait Anxiety } \\
\text { Inventory } \\
\text { (iii) Caregiver Strain } \\
\text { Scale } \\
\text { (iv) Positive Aspects of } \\
\text { Caregiving }\end{array}$ & $\begin{array}{l}\text { Length: } 4 \text { weeks. } \\
\text { Intervention: }(n=150) \\
\text { access to asynchronous } \\
\text { web-based modules } \\
\text { and videos (caregiver's } \\
\text { friend: dealing with } \\
\text { dementia) and } \\
\text { educational materials } \\
\text { tailored to care } \\
\text { recipient and care giver } \\
\text { characteristics. The } \\
\text { coping strategies } \\
\text { presented throughout } \\
\text { focused on problem- } \\
\text { focused techniques and } \\
\text { social support skills. } \\
\text { Wait list control: } \\
\text { ( } n=149) \text { usual } \\
\text { treatment, then given } \\
\text { access to the } \\
\text { intervention. }\end{array}$ & $\begin{array}{l}\text { Those in the } \\
\text { intervention group } \\
\text { reported significant } \\
\text { improvements in } \\
\text { depression, anxiety, } \\
\text { level and frequency of } \\
\text { stress, caregiver strain, } \\
\text { self-efficacy, intention } \\
\text { to seek help, and } \\
\text { positive aspects of } \\
\text { caregiving. }\end{array}$ \\
\hline
\end{tabular}

Length: self-paced; 5-6 months from baseline with midpoint assessment at 3 months.

Intervention: $(n=149)$ eight self-paced interactive web-based modules (Mastery over Dementia) which included problemsolving, relaxation, arranging help from others, cognitive restructuring, and

(ii) HADS

(iii) Informal Care Scale (self-perceived

Blom et al. Asynchronous web[47]* based educational modules with email
Caregivers only Family caregivers of persons with dementia pressure subscale)

(iv) RMBPC

(v) Short Sense of Competence Questionnaire (vi) Pearlin Mastery Scale assertiveness training, plus a booster summary session were delivered. After each session, participants completed and

submitted homework to a coach who returned electronic feedback.

Comparison: $(n=96)$ E-bulletins (digital newsletters) with practical information on providing care for someone with dementia were sent by email every 3 weeks over nearly 6 months. There was no contact with a coach.
Depression and anxiety improved significantly in the intervention group. Noteworthy, even older caregivers (>65 years) can benefit from a web-based intervention to reduce psychological symptoms. 
TABle 4: Continued.

\begin{tabular}{|c|c|c|c|c|c|}
\hline \multicolumn{6}{|c|}{ Web interventions $(n=14)$} \\
\hline Authors & & Caregiver group & Study measures & $\begin{array}{l}\text { Intervention } \\
\text { description }\end{array}$ & Findings \\
\hline $\begin{array}{l}\text { Chih et al. } \\
{[48]^{*}}\end{array}$ & $\begin{array}{l}\text { Asynchronous web- } \\
\text { based educational } \\
\text { materials, interactive } \\
\text { electronic patient } \\
\text { reported outcomes, } \\
\text { medical online } \\
\text { platform which } \\
\text { generated emails to } \\
\text { clinicians in certain } \\
\text { situations }\end{array}$ & $\begin{array}{l}\text { Caregiver-care } \\
\text { recipient dyads } \\
\text { Family caregivers of } \\
\text { persons with advanced } \\
\text { stage lung, breast, and } \\
\text { prostate cancer in } \\
\text { outpatient clinics }\end{array}$ & $\begin{array}{l}\text { (i) Family Care } \\
\text { Inventory (caregiver } \\
\text { preparedness subscale) } \\
\text { (ii) Caregiver Burden } \\
\text { Inventory (caregiver } \\
\text { physical burden } \\
\text { subscale) } \\
\text { (iii) Shortened Version } \\
\text { of the Profile of Mood } \\
\text { States (negative mood } \\
\text { items) }\end{array}$ & $\begin{array}{l}\text { Length: } 52 \text { weeks, with } \\
6 \text { - and } 12 \text {-month } \\
\text { follow-up. } \\
\text { Intervention: ( } n=118 \\
\text { dyads) asynchronous } \\
\text { access to an interactive } \\
\text { medical online } \\
\text { platform with a wide } \\
\text { variety of practical, } \\
\text { cancer-specific } \\
\text { educational and self- } \\
\text { help coaching } \\
\text { resources. Also given } \\
\text { rating scales to report } \\
\text { physical and } \\
\text { psychological } \\
\text { symptoms of caregiver } \\
\text { and patient. Clinical } \\
\text { reports of those } \\
\text { symptoms were } \\
\text { generated and made } \\
\text { available to their } \\
\text { medical providers, } \\
\text { including an email alert } \\
\text { when reported } \\
\text { symptom intensity } \\
\text { crossed a threshold. } \\
\text { Comparison: ( } n=117 \\
\text { dyads) access to the } \\
\text { interactive website, but } \\
\text { this did not generate a } \\
\text { clinical report to their } \\
\text { clinical team. }\end{array}$ & $\begin{array}{c}\text { Caregiver burden and } \\
\text { subjective preparedness } \\
\text { did not differ between } \\
\text { groups at 6- and 12- } \\
\text { month } \\
\text { postintervention, but } \\
\text { caregiver reports of } \\
\text { negative mood were } \\
\text { lower for those in the } \\
\text { intervention group. }\end{array}$ \\
\hline $\begin{array}{l}\text { Hattink } \\
\text { et al. [49]* }\end{array}$ & $\begin{array}{l}\text { Web-based training } \\
\text { modules plus online } \\
\text { peer and expert } \\
\text { communities for } \\
\text { support and } \\
\text { information exchange }\end{array}$ & $\begin{array}{c}\text { Caregivers only } \\
\text { Informal caregivers of } \\
\text { persons with dementia; } \\
\text { volunteers in dementia } \\
\text { care; professional } \\
\text { caregivers }\end{array}$ & $\begin{array}{l}\text { (i) Alzheimer's Disease } \\
\text { Knowledge Scale } \\
\text { (ii) Alzheimer's Disease } \\
\text { Survey } \\
\text { (iii) Approaches to } \\
\text { Dementia } \\
\text { Questionnaire } \\
\text { (iv) Interpersonal } \\
\text { Reactivity Index } \\
\text { (v) } 3 \text { Researcher- } \\
\text { Developed Items } \\
\text { (vi) Short Sense of } \\
\text { Competence } \\
\text { Questionnaire }\end{array}$ & $\begin{array}{l}\text { Length: } 2 \text { to } 4 \text { months. } \\
\text { Intervention: }(n=37) \\
\text { participants were given } \\
\text { access to web-based } \\
\text { interactive training } \\
\text { modules plus online } \\
\text { peer support and } \\
\text { expert communities for } \\
\text { information exchange. } \\
\text { Wait list control: } \\
(n=46) \text { participants } \\
\text { were given access to the } \\
\text { training modules, } \\
\text { online support, and } \\
\text { expert communities } \\
\text { after } 4 \text { months. }\end{array}$ & $\begin{array}{l}\text { Lay people in both the } \\
\text { intervention and } \\
\text { control conditions } \\
\text { showed positive change } \\
\text { over time in reporting a } \\
\text { person-centered } \\
\text { approach to dementia } \\
\text { care. No other } \\
\text { measures of knowledge } \\
\text { about and attitudes } \\
\text { toward dementia were } \\
\text { statistically significant } \\
\text { across groups among } \\
\text { laypeople or } \\
\text { professionals. In pre- } \\
\text { postcomparisons, } \\
\text { participants in the } \\
\text { intervention group } \\
\text { reported less distress in } \\
\text { tense situations, more } \\
\text { empathy and concern } \\
\text { for the well-being of } \\
\text { other people and } \\
\text { feeling better able to }\end{array}$ \\
\hline
\end{tabular}


TABLe 4: Continued.

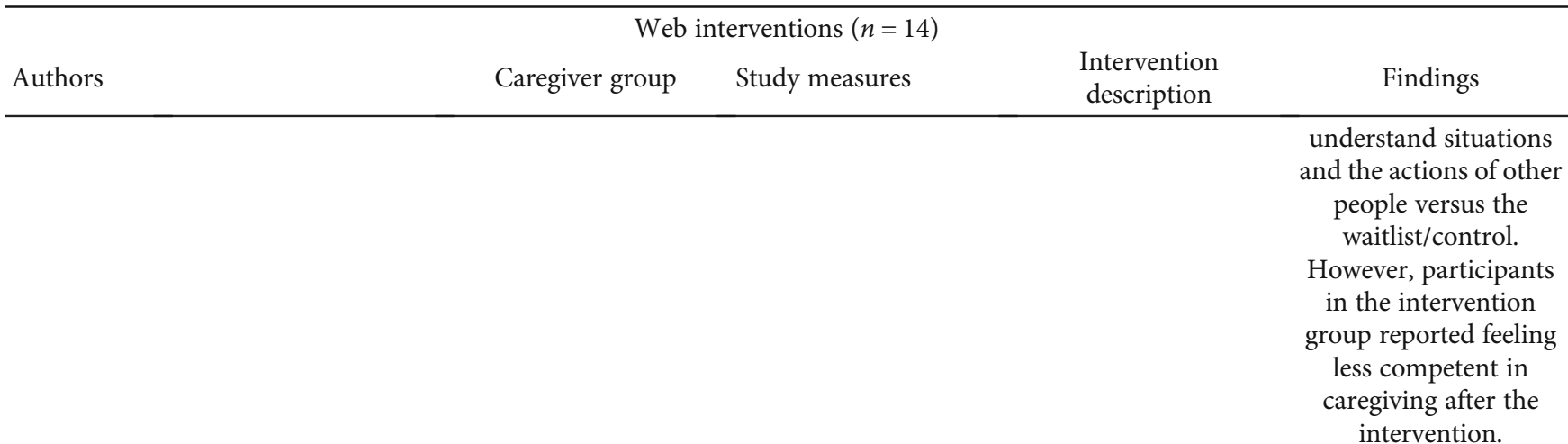
intervention.

\begin{abstract}
Asynchronous (educational modules with videos available

Kajiyama et al. [50]*

available and

encouraged
\end{abstract}
Caregivers only
Family caregivers of
older adults with dementia
(i) PSS
(ii) RMBPC
(iii) CES-D
(vi) Perceived Quality of Life

\section{Length: 12 weeks.}

Intervention: $(n=75)$

asynchronous access to an online or DVD

intervention program

Caregivers only Mostly employed (part- or full-time)

Klemm et al. Asynchronous web[51]* based adults $(\geq 40)$ caregivers

of persons with a

chronic disease, with 9

(i) CES-D

(ii) Modified CSI

retired or full-time caregivers as well which included 6 skill building modules with video illustrations, as well as modules focused on reducing stress and negative thoughts designed to be completed in set order.

They also received a workbook and were encouraged to fill it out. Comparison: $(n=75)$ received access to a website containing similar navigational features, with information about dementia as well as links to video-taped information plus booklet materials from various health agencies.

Length: 12 weeks. Professionally facilitated intervention group: $(n=20)$ a psychiatric nurse provided

psychoeducation

Perceived stress decreased significantly over time in the intervention group, whereas there was no significant change in perceived stress in the comparison group. The groups did not differ in the amount of change over time in feeling "bothered" by care recipients' memory deficits and behavior problems, nor did they differ in amount of change in depression or perceived quality of life.

The two intervention groups showed significant improvements in depressive symptoms and quality life as compared to the through weekly posts on topics related to caregiving and responded to questions as requested. Moderated intervention: $(n=27)$ primarily peer-

directed, this group was moderated by the primary investigator and utilized an unstructured format control group; the two intervention groups did not differ significantly on depressive symptoms or quality of life. There were no significant differences between groups for caregiver strain. Results suggest providing support to caregivers, regardless of format, can help improve 
TABle 4: Continued.

\begin{tabular}{|c|c|c|c|c|c|}
\hline \multicolumn{6}{|c|}{ Web interventions $(n=14)$} \\
\hline Authors & & Caregiver group & Study measures & $\begin{array}{l}\text { Intervention } \\
\text { description }\end{array}$ & Findings \\
\hline & & & & $\begin{array}{l}\text { once initial guidelines } \\
\text { and purpose had been } \\
\text { posted. } \\
\text { Usual care: }(n=39) \\
\text { standard care. No } \\
\text { access to website and } \\
\text { received no treatment. }\end{array}$ & $\begin{array}{l}\text { quality of life and } \\
\text { decrease depressive } \\
\text { symptoms. }\end{array}$ \\
\hline $\begin{array}{l}\text { Marziali and } \\
\text { Donahue } \\
{[52]^{*}}\end{array}$ & $\begin{array}{l}\text { Asynchronous website, } \\
\text { synchronous web- } \\
\text { based } \\
\text { videoconferencing, } \\
\text { email }\end{array}$ & $\begin{array}{l}\text { Caregivers only } \\
\text { Family caregivers of } \\
\text { older adults with } \\
\text { neurodegenerative } \\
\text { diseases }\end{array}$ & $\begin{array}{l}\text { (i) Composite of the } \\
\text { HSQ-12 and the MOS- } \\
36 \\
\text { (ii) CES-D } \\
\text { (iii) Caregiver Report: } \\
\text { Activities of Daily } \\
\text { Living and } \\
\text { Instrumental Activities } \\
\text { of Daily Living } \\
\text { Performed for Care } \\
\text { Recipient, Plus Stress } \\
\text { Rating for Each } \\
\text { (vi) RMBPC } \\
\text { (v) Multidimensional } \\
\text { Scale of Perceived } \\
\text { Social Support }\end{array}$ & $\begin{array}{l}\text { Length: } 10 \text { weeks. } \\
\text { Intervention: }(n=33) \\
\text { asynchronous access to } \\
\text { a website with } \\
\text { information, email, and } \\
\text { threaded discussion; a } \\
\text { point-to-point video- } \\
\text { conferencing link } \\
\text { supported caregivers' } \\
\text { participation in a } \\
\text { manual-guided } \\
\text { psychosocial support } \\
\text { group for } 10 \text { weekly } \\
\text { sessions, followed by an } \\
\text { additional two sessions } \\
\text { led by a group member. } \\
\text { Usual care: }(n=33) \\
\text { standard care. No- } \\
\text { intervention condition. }\end{array}$ & $\begin{array}{l}\text { The intervention group } \\
\text { showed reliable } \\
\text { adherence to the } \\
\text { manual-guided support } \\
\text { group and similar } \\
\text { themes were noted as } \\
\text { compared to face-to- } \\
\text { face support groups. } \\
\text { The intervention group } \\
\text { also reported } \\
\text { significantly less stress } \\
\text { postintervention, while } \\
\text { the control group } \\
\text { reported an increase in } \\
\text { stress. }\end{array}$ \\
\hline $\begin{array}{l}\text { Petranovich } \\
\text { et al. [53]* }\end{array}$ & $\begin{array}{l}\text { Synchronous web- } \\
\text { based, in-person } \\
\text { (initial visit for } \\
\text { intervention group } \\
\text { only) }\end{array}$ & $\begin{array}{c}\text { Caregivers only } \\
\text { Primary family } \\
\text { caregivers of } \\
\text { adolescents (12-17 } \\
\text { years old) with mild to } \\
\text { severe TBI within prior } \\
1-7 \text { months }\end{array}$ & $\begin{array}{l}\text { (i) SCL-90-R } \\
\text { (ii) CES-D } \\
\text { (iii) CSES }\end{array}$ & $\begin{array}{l}\text { Length: } 6 \text { months; } \\
\text { follow-up at 6-, 12-, } \\
\text { and 18-month } \\
\text { postbaseline. } \\
\text { Intervention: ( } n=65) \\
\text { an initial 2-day } \\
\text { intervention training } \\
\text { program was provided } \\
\text { to participating } \\
\text { therapists. Family } \\
\text { caregiver participants } \\
\text { received an initial 1- } \\
\text { day in-home training } \\
\text { session to introduce the } \\
\text { family intervention } \\
\text { which focused on } \\
\text { problem-solving } \\
\text { training, } \\
\text { communication skills, } \\
\text { self-regulation, and } \\
\text { anger management and } \\
\text { to identify family goals } \\
\text { to be addressed in the } \\
\text { intervention. } \\
\text { Participants received a } \\
\text { detailed manual and } \\
\text { completed a series of } \\
\text { online modules and } \\
\text { Skype sessions with a } \\
\text { licensed therapist. Up } \\
\text { to } 4 \text { supplemental }\end{array}$ & $\begin{array}{l}\text { The intervention was } \\
\text { effective in reducing } \\
\text { parent distress but had } \\
\text { minimal effect on } \\
\text { depression and self- } \\
\text { efficacy. The } \\
\text { intervention was more } \\
\text { effective in reducing } \\
\text { distress in low-income } \\
\text { families at 12- and 18- } \\
\text { month follow-up than } \\
\text { the control group. } \\
\text { While depression was } \\
\text { greater for caregivers of } \\
\text { adolescents with severe } \\
\text { TBI versus adolescents } \\
\text { with moderate TBI, } \\
\text { these differences did } \\
\text { not continue through } \\
\text { the 12- and 18-month } \\
\text { follow-up. }\end{array}$ \\
\hline
\end{tabular}


TABLe 4: Continued.

\begin{tabular}{|c|c|c|c|}
\hline \multirow[b]{2}{*}{ Authors } & \multicolumn{3}{|c|}{ Web interventions $(n=14)$} \\
\hline & Caregiver group & Study measures & $\begin{array}{l}\text { Intervention } \\
\text { description }\end{array}$ \\
\hline & & & $\begin{array}{l}\text { modules were available } \\
\text { for use as determined } \\
\text { by the therapist. } \\
\text { Comparison: ( } n=67) \text { a } \\
\text { self-guided, web-based } \\
\text { program which } \\
\text { provided information } \\
\text { about TBI and online } \\
\text { resources. Participants } \\
\text { were asked to access } \\
\text { this } 1 \text { hour per week. }\end{array}$ \\
\hline
\end{tabular}

Pierce et al. Asynchronous web[54]

based education
materials, email

Caregivers only Family caregivers of adult first-time stroke survivors discharged from rehabilitation center; novice Internet users (i) CES-D

(ii) SWLS

(iii) Functional Independence Measure (iv) Healthcare UsageResearcher Developed
Length: 52 weeks. Intervention: $(n=51)$ asynchronous access to web-based educational materials, customized

"tip sheets", email forum to ask questions of a multidisciplinary team (e.g., nurses, therapists, social worker, physician), and a nonstructured, nursefacilitated email forum among all participants.

Control: $(n=52)$ received usual medical care and were asked not to use the Internet for the year of the study.

No differences were found in reported depression and life satisfaction between the intervention and usual care groups. Significant differences were found between the groups on survivors' visits to hospital emergency departments (33\% fewer visits for the intervention group) and number of hospital readmissions $(66 \%$

fewer readmissions for the intervention group). No differences were found in number of visits to their healthcare providers.

Length: 4-6 months, no follow-up. Intervention: $(n=20)$ participants received an initial in-home visit

to introduce the intervention designed to increase positive parenting skills and improve caregiver stress management.

Participants also intervention group only), synchronous

Raj et al. [55] web-based videoconferencing, asynchronous webbased educational modules
Caregivers only

(i) Symptom Checklist90-Revised (Global Parents/legal guardians of children with TBI

(ii) CES-D

(iii) Parenting Stress Index $\left(3^{\text {rd }}\right)$

(iv) CSES received 10 core webbased sessions and up to 4 supplemental sessions. Each session included self-guided web content, followed by a videoconference call with a therapist to discuss content and practice parenting skills with live feedback.

Comparison: $(n=20)$
Parent income moderated treatment effects on parent psychological distress. Specifically, lowerincome parents in the parenting skills group reported significant reductions in psychological distress compared with lowerincome parents in the control group. No differences for caregiver depression, parenting stress and caregiver efficacy between the two groups over time. 
TABLe 4: Continued.

Web interventions $(n=14)$

Authors

Caregiver group Study measures

Intervention

description

Findings

participants received

links to TBI web

resources.

Length: 11 weeks, with

1-month follow-up.

Intervention: $(n=19$

dyads) asynchronous

access to educational

videos and an online

library of educational

materials related to

stroke, caregiving, and

coping. Participants

took part in guided

Synchronous (audio only, Internet-based support groups) \&

Smith et al. asynchronous options [56]*

$$
\text { (online }
$$

library/educational videos, message boards, email) (i) CES-D

Caregiver-care recipient dyads

Wives caring for husbands surviving stroke (ii) Mastery Scale (9 items)

(iii) Self-Esteem Scale

(iv) MOS Social Support Survey-11 items online synchronous audio-only chat sessions with other

wives in the study twice weekly for a total of 17 sessions, and an email message board enabling messages exchanged with the nurse facilitator and with each other.

Comparison: ( $n=19$ dyads) asynchronous access to an online educational resource library and completed measures at baseline and at two follow-up intervals.

Length: 25 weeks; parenting stress was measured at baseline \& 25 weeks; all other domains were measured at baseline, 4, $10,19, \& 25$ weeks.

Intervention: $(n=111)$ children's ADHD

Telemental Health Treatment Studyhybrid telehealth service-delivery model with combined pharmacotherapy and caregiver behavior training for reducing children's ADHD-

related symptoms and caregivers' distress.

Participants received 6 videoconferencing sessions led by a psychiatrist on
Controlling for baseline depression, caregivers in the intervention group reported significantly lower depression one-month postintervention as compared to the control group. No significant treatment effects were noted for other outcomes.
Overtime, caregivers in both service models reported significantly decreased levels of

distress and depression symptoms and increased levels of family empowerment. Effects were significantly greater for caregivers in the intervention group. Further, combined child symptom improvements mediated reductions in parenting stress and caregiver strain, and improvements in caregiver strain were significantly mediated by treatment-induced decreases in child ODD symptoms. 
TABLe 4: Continued.

\begin{tabular}{|c|c|c|c|c|}
\hline \multicolumn{5}{|c|}{ Web interventions $(n=14)$} \\
\hline Authors & Caregiver group & Study measures & $\begin{array}{c}\text { Intervention } \\
\text { description }\end{array}$ & Findings \\
\hline & & & $\begin{array}{l}\text { pharmacotherapy, } \\
\text { immediately followed } \\
\text { by } 6 \text { in-person sessions } \\
\text { of caregiver behavior } \\
\text { training from master's } \\
\text { level therapists spaced } \\
3 \text { to } 4 \text { weeks apart. } \\
\text { Comparison: }(n=112) \\
\text { received primary care } \\
\text { with a single } \\
\text { teleconsultation } \\
\text { session. }\end{array}$ & \\
\hline
\end{tabular}

Length: 16-24 weeks. Intervention: $(n=26)$ manualized problemsolving therapy and cognitive behavioral skills training through synchronous online videoconferencing sessions, plus one inperson in-home initial interview. During the initial meeting, the therapist conducted a structured interview and elicited goals

Synchronous webbased

Wade et al. [58]* videoconferencing and asynchronous educational modules with tailoring and videos
Caregiver-care recipient dyads Families of children (ages 5-16) with moderate to severe TBI between 1 and 24 months previously. (i) Social ProblemSolving Index-Short

(ii) CES-D

(iii) Anxiety Inventory

(iv) Symptom

Checklist-90

(v) Global Severity Index

identified by caregivers. Subsequent meetings were conducted via synchronous online videoconferencing, and in-between times, the family completed webbased self-guided materials. There were 8 core sessions, with 4 additional

supplemental sessions. Participants also received Internet access to a home page linking them to brain injury web sites and resources. Comparison: $(n=20)$ usual psychosocial care, plus access to the home page and links.

Length: 6 months.

Synchronous webbased

videoconferencing,

Wade et al. asynchronous web[59]

\section{Caregiver-care} recipient dyads Family caregivers of adolescents (ages 1118) with moderate to severe TBI between 3 and 19 months previously (i) Social Problem-

Solving Index

(ii) CES-D

(iii) Symptom

Checklist-90

Global Severity Index (initial visit

intervention group only)
Intervention: $(n=21)$ web-based interactive teaching modules for

10 core topics, with up to six supplemental modules. Each module was followed by a point-to-point
The intervention group reported significantly

less depression, anxiety, and global distress at follow-up than did the control group, after controlling for baseline symptom levels. No significant findings were noted for problem-solving.
Both groups improved significantly over time in problem-solving, depression, and destress. 
TABLe 4: Continued.

\begin{tabular}{|c|c|c|c|c|}
\hline \multicolumn{5}{|c|}{ Web interventions $(n=14)$} \\
\hline Authors & Caregiver group & Study measures & $\begin{array}{c}\text { Intervention } \\
\text { description }\end{array}$ & Findings \\
\hline & & & $\begin{array}{l}\text { videoconference } \\
\text { session to practice the } \\
\text { module skills together. } \\
\text { Structured materials } \\
\text { included problem- } \\
\text { solving strategies and } \\
\text { TBI information, as } \\
\text { well as individualized } \\
\text { materials for needs } \\
\text { such as pain } \\
\text { management. } \\
\text { Comparison: }(n=20) \\
\text { the same technology } \\
\text { resources and online } \\
\text { TBI-specific } \\
\text { educational modules } \\
\text { but no problem-solving } \\
\text { modules or interactive } \\
\text { video sessions; they } \\
\text { were encouraged to } \\
\text { spend one hour/week } \\
\text { reviewing the } \\
\text { informational websites. }\end{array}$ & \\
\hline
\end{tabular}

*Study reported significant improvement in at least one target outcome in the intervention group as compared to the control/comparison group. CESD: Center for Epidemiological Studies-Depression Scale; HADS: Hospital Anxiety and Depression Scale; CSI: Caregiver Strain Index; CQoL-I: Caregiver Quality of Life Index; CSES: Caregiver Self-Efficacy Scale; TBI: traumatic brain injury; ADHD: attention deficit hyperactivity disorder; ODD: oppositional defiant disorder; SWLS: Satisfaction with Life Scale; PSS: Perceived Stress Scale; MOS: Medical Outcomes Study; HSQ: Health Status Questionnaire; PHQ: Patient Health Questionnaire; RMBPC: Revised Memory and Behavioral Problem Checklist.

2.4. Data Analytic Strategy. Analysis of systematic review findings was organized based on the primary telecommunication modalities used in delivering caregiver interventions. Studies were placed into three different categories: (a) telephone interventions, (b) web interventions, and (c) combination of telephone and web interventions. This data analytic strategy was implemented due to limited variation in caregiver populations. Over half of included studies targeted family caregivers of older adults with dementia or stroke. Two advantages emerged from this approach: (a) optimal differentiation across caregiver telehealth outcome studies and (b) substantive methodological and conceptual comparisons. Only a small percentage of included studies reported caregiver-care recipient dyadic results. Thus, this review addressed caregiver outcomes only.

Data analysis focused primarily on counts and percentages across the major elements of the review (i.e., characteristics of caregiver samples, intervention strategies, outcomes, and caregiver applications and user controls). First, descriptive statistics on caregiver sample characteristics were calculated for both the overall sample of caregivers and separately for each telecommunication delivery mode. Similarly, the number and percentage of specific types of intervention strategies were assessed for the overall sample of studies and separately for each of the three categories of delivery modalities.

Second, vote counting (i.e., number and percentage) of statistically significant caregiver target outcomes was conducted for both the overall sample and separately for each of the three telecommunication modalities. The term, improved outcome, was used only if the target outcome of the intervention group was statistically significant compared to the comparison/control groups (Tables 3-5). Target outcomes included psychological well-being, physiological functioning, caregiving skills, social functioning, problemsolving/goal setting, and quality of life. Studies were included in this count once. The rationale for this procedure was to facilitate accurate and consistent percentage calculations of the total number of significant studies versus the total number of studies and for each of the three modality categories.

Last, the number and percentage of caregiver applications and user control features were assessed for both the overall sample and separately for each of the three telecommunication modalities (Table 6).

\section{Results}

\subsection{Characteristics of Telehealth Randomized Controlled Trials across Modalities}

3.1.1. Samples, Journal Outlets, and Study Locations. A total of 57 randomized controlled trials evaluating the efficacy of telehealth interventions for caregivers of persons with chronic health conditions were included in this systematic review (Figure 1). Tables 3-5 summarize the key characteristics and outcomes of these studies, including telehealth delivery modalities, type of caregiver sample, primary outcome measures, intervention description, and key findings. Of the 
TABLE 5: Combined telephone and web interventions for caregivers of persons with chronic health conditions.

\begin{tabular}{|c|c|c|c|c|c|}
\hline \multicolumn{6}{|c|}{ Combined telephone and web interventions $(n=10)$} \\
\hline Authors & & Caregiver group & Study measures & Intervention description & Findings \\
\hline $\begin{array}{l}\text { Eisdorfer } \\
\text { et al. } \\
{[60]^{*}}\end{array}$ & $\begin{array}{l}\text { In-person, telephone, } \\
\text { web-based supplement } \\
\text { (with telephone } \\
\text { technology, local } \\
\text { resources, online } \\
\text { discussion groups, family } \\
\text { conferences) }\end{array}$ & $\begin{array}{l}\text { Caregivers only } \\
\text { Family } \\
\text { caregivers living } \\
\text { with older adults } \\
\text { with Alzheimer's }\end{array}$ & $\begin{array}{l}\text { (i) CES-D } \\
\text { (ii) RMBPC } \\
\text { (iii) Researcher- } \\
\text { Developed Likert Scaled } \\
\text { Item on Satisfaction with } \\
\text { Social Support }\end{array}$ & $\begin{array}{l}\text { Length: } 12 \text { months, with } \\
\text { assessments at } 6,12, \& 18 \\
\text { months. } \\
\text { Intervention (SET) group } \\
\text { 1: ( } n=75 \text { ) received } \\
\text { structural ecosystems } \\
\text { therapy, a family } \\
\text { intervention which } \\
\text { identifies and targets the } \\
\text { specific problems } \\
\text { caregivers are } \\
\text { experiencing, the range of } \\
\text { usable resources available } \\
\text { to the caregiver and their } \\
\text { formal support systems, } \\
\text { the range of community } \\
\text { resources available and } \\
\text { accessible to the family, } \\
\text { and the capacity of the } \\
\text { caregivers and their } \\
\text { family to collaborate in } \\
\text { the caregiving effort. } \\
\text { Intervention (SET+CTIS) } \\
\text { group } 2: \text { ( } n=77 \text { ) } \\
\text { additionally received a } \\
\text { computer-telephone } \\
\text { integrated system } \\
\text { designed to augment the } \\
\text { therapeutic intervention } \\
\text { by facilitating linkages of } \\
\text { the caregivers with their } \\
\text { family, the therapist, and } \\
\text { supportive resources } \\
\text { outside of the home. } \\
\text { Attention control: ( } n=73 \text { ) } \\
\text { participants received } \\
\text { minimal support through } \\
\text { nondirective, } \\
\text { noninformative telephone } \\
\text { materials. }\end{array}$ & $\begin{array}{l}\text { The SET alone did not } \\
\text { have a significant effect on } \\
\text { depression for most } \\
\text { caregivers, except for } \\
\text { Cuban American wives. } \\
\text { SET+CTIS was effective } \\
\text { in lowering caregiver } \\
\text { depression at } 6 \text { and } 18 \\
\text { months. The MSC } \\
\text { showed moderate } \\
\text { decreases for white } \\
\text { caregiver spouses but was } \\
\text { associated with higher } \\
\text { depression scores for } \\
\text { Cuban American spouses. } \\
\text { Cuban American } \\
\text { husbands tended to show } \\
\text { reductions in depression } \\
\text { for SET+CTIS but } \\
\text { increases in depression } \\
\text { for the other two groups. }\end{array}$ \\
\hline $\begin{array}{l}\text { Grover } \\
\text { et al. } \\
{[61]^{*}}\end{array}$ & $\begin{array}{l}\text { Intervention group only: } \\
\text { asynchronous (interactive } \\
\text { web-based tailored } \\
\text { educational modules), } \\
\text { choice of phone or email } \\
\text { guidance from } \\
\text { psychologist and } \\
\text { psychotherapist }\end{array}$ & $\begin{array}{l}\text { Caregivers only } \\
\text { Caregivers of } \\
\text { persons with } \\
\text { subclinical \& } \\
\text { clinical anorexia } \\
\text { nervosa }\end{array}$ & $\begin{array}{l}\text { (i) HADS } \\
\text { (ii) Experience of } \\
\text { Caregiving Inventory } \\
\text { (iii) Level of Expressed } \\
\text { Emotion Scale } \\
\text { (iv) Accommodation } \\
\text { and Enabling Scale for } \\
\text { Eating Disorders } \\
\text { (v) The Eating Disorder } \\
\text { Symptom Impact Scale } \\
\text { (vi) Service Utilization } \\
\text { Questionnaire }\end{array}$ & $\begin{array}{l}\text { Length: } 4 \text { months, with a } \\
\text { 2-month follow-up } \\
\text { postintervention. } \\
\text { Intervention: }(n=34) \\
\text { asynchronous web-based } \\
\text { access to a multimedia, } \\
\text { online program over } 4 \\
\text { months which included } 8 \\
\text { interactive web-based } \\
\text { tailored modules based on } \\
\text { systemic, cognitive } \\
\text { behavioral, and } \\
\text { motivational interviewing } \\
\text { frameworks. Workbooks } \\
\text { and other materials were } \\
\text { made available for }\end{array}$ & $\begin{array}{l}\text { The intervention group } \\
\text { showed more reduction in } \\
\text { reported anxiety than the } \\
\text { usual care group. The } \\
\text { groups did not show } \\
\text { significant differences in } \\
\text { change on the other five } \\
\text { measures. }\end{array}$ \\
\hline
\end{tabular}


TABLe 5: Continued.

Combined telephone and web interventions $(n=10)$

Authors Caregiver group Study measures

Intervention description

Findings

download. Moderated

message boards were also available. Weekly

guidance from a therapist

was available up to 20

minutes a week by phone

or email. These were

tailored to each

caregiver's needs with

support and

encouragement or

referrals to specific parts

of the program.

Usual care/waitlist:

$(n=30)$ access to usual

eating disorder resources

(e.g., telephone hotline

services [support only, no

referrals or advice given,

not necessarily the same

person each time a person

calls in], email support

services, support groups,

and moderated message

board and text

messaging). Provided

access to the intervention after the study.

Length: 4 to 6 months.

Description: caregivers were stratified into 2

cohorts based upon use $(n=155)$ or nonuse

( $n=74)$ of the Internet, then randomized.

Intervention: $(n=107)$

electronic content (i.e., video vignettes, written information, brief

Internet or touch screen telehealth device

Hicken

et al.

[62]* connected through a telephone line (for subjects unfamiliar with (i) ZBI

(ii) MARWIT (sacrifice and burden, heartfelt

Caregivers only Family Internet), versus telephone only caregivers of veterans with dementia or a cognitive disorder sadness and longing, \& worry and isolation subscales)

(iii) PHQ

(iv) 2-items (family caregiving burden causing family conflict \& hardship)

(v) Desire to Institutionalize Scale assessments) on dementia progression, caregiving skills, health topics, and caregiver health were accessed 3 days per week with care manager oversight and follow-up electronically.

Comparison: $(n=122)$ printed educational materials and a DVD covering content like that introduced electronically were provided, in addition to monthly telephone calls from a care manager for support.
Among home Internet users, receiving the Internet plus case management intervention predicted a decrease in reported feelings of isolation, compared to receiving the telephone only intervention. Among non-Internet users, receiving telehealth and case management predicted a decrease in reported family hardship associated with caregiving, compared to those receiving the telephone only intervention. 
TABLe 5: Continued.

\begin{tabular}{|c|c|c|c|c|c|}
\hline \multicolumn{6}{|c|}{ Combined telephone and web interventions $(n=10)$} \\
\hline Authors & & Caregiver group & Study measures & Intervention description & Findings \\
\hline $\begin{array}{l}\text { Mahoney } \\
\text { et al. } \\
{[63]^{*}}\end{array}$ & $\begin{array}{l}\text { Telephone; a computer- } \\
\text { mediated system using } \\
\text { interactive voice response } \\
\text { (IVR) with a telephone } \\
\text { interface }\end{array}$ & $\begin{array}{l}\text { Caregivers only } \\
\text { Male and female } \\
\text { family caregivers } \\
\text { of older adults } \\
\text { with Alzheimer's }\end{array}$ & $\begin{array}{l}\text { (i) RMBPC } \\
\text { (ii) CES-D } \\
\text { (iii) SAI }\end{array}$ & $\begin{array}{l}\text { Length: } 12 \text { months, with a } \\
\text { 6-month follow-up. } \\
\text { Intervention: ( } n=49) \\
\text { received a computer- } \\
\text { mediated system using } \\
\text { interactive voice response } \\
\text { (IVR) with a telephone } \\
\text { interface. When } \\
\text { caregivers called, the IVR } \\
\text { queried about problem } \\
\text { behaviors and responded } \\
\text { with targeted } \\
\text { information. Study } \\
\text { personnel were alerted } \\
\text { when a caregiver reported } \\
\text { continuing problem } \\
\text { behaviors and increasing } \\
\text { stress levels during any 3- } \\
\text { week period. The system } \\
\text { also provided voice-mail } \\
\text { linkage to experts in } \\
\text { Alzheimer's and related } \\
\text { dementias, a voice-mail } \\
\text { telephone support group, } \\
\text { and a distraction call for } \\
\text { care recipients. } \\
\text { Usual care: ( } n=51) \\
\text { standard care and } \\
\text { educational materials. }\end{array}$ & $\begin{array}{l}\text { No main effects were } \\
\text { found on any measure. In } \\
\text { post hoc analyses, among } \\
\text { caregivers who reported } \\
\text { low- to mid-level mastery } \\
\text { at baseline }(N=32) \text {, those } \\
\text { in the intervention group } \\
\text { showed a decrease in } \\
\text { bother, depression and } \\
\text { anxiety relative to the } \\
\text { comparison group. }\end{array}$ \\
\hline
\end{tabular}

Length: biweekly contacts for the duration of hospice stay (average contacts: intervention $=$ 3.85; control = 3.98); caregiver follow-up interview 30 days after death of care recipient. Intervention: $(n=223)$ participants connected with hospice staff using telephone or online videoconferencing to discuss the care recipients' condition, identify concerns and questions, and discuss plan of care. Usual care: $(n=223)$ standard care.

Length: 12 months, with 6- and 12-month followup. Intervention: $(n=189)$ participants received weekly automated selfcare support telephone calls with notifications about problems sent to
The intervention group reported belief that the care recipient's pain could be managed and perceived that the care recipient's pain was better managed versus the control group. As caregiver pain management perceptions improved, caregiver anxiety significantly decreased.
Piette

et al.

[65]*
Telephone, asynchronous web-based
Caregivers only Informal

caregivers living outside the

home of persons with heart failure (i) CSI

(ii) CES-D (10-item)

(iii) Researcher-

Developed Items regarding Time Spent

Helping the Care Recipient, Involved in Transportation, and 
TABle 5: Continued.

\begin{tabular}{|c|c|c|c|c|c|}
\hline \multicolumn{6}{|c|}{ Combined telephone and web interventions $(n=10)$} \\
\hline Authors & & Caregiver group & Study measures & Intervention description & Findings \\
\hline & & & $\begin{array}{l}\text { Assisting with } \\
\text { Medications }\end{array}$ & $\begin{array}{l}\text { clinicians, plus email } \\
\text { summaries and } \\
\text { suggestions for self-care } \\
\text { assistance automatically } \\
\text { sent to caregivers. } \\
\text { Comparison: }(n=180) \\
\text { same treatment minus the } \\
\text { emailed summaries and } \\
\text { suggestions for caregivers. }\end{array}$ & $\begin{array}{l}\text { reporting more burden at } \\
\text { baseline. Those in the } \\
\text { intervention group who } \\
\text { spent the most time } \\
\text { providing self-care } \\
\text { support at baseline had } \\
\text { significant decreases at } \\
\text { both follow-ups. More } \\
\text { caregivers increased their } \\
\text { involvement in medical } \\
\text { visits and medication } \\
\text { adherence. }\end{array}$ \\
\hline $\begin{array}{l}\text { Powell } \\
\text { et al. } \\
{[66]^{*}}\end{array}$ & $\begin{array}{c}\text { Telephone, asynchronous } \\
\text { web-based educational } \\
\text { modules }\end{array}$ & $\begin{array}{l}\text { Caregivers only } \\
\text { Caregivers of } \\
\text { adults with } \\
\text { moderate to } \\
\text { severe TBI } \\
\text { discharged from } \\
\text { a level } 1 \text { trauma } \\
\text { center }\end{array}$ & $\begin{array}{l}\text { (i) BCOS (adapted for } \\
\text { TBI } \\
\text { (ii) BSI } \\
\text { (iii) Life Satisfaction } \\
\text { Scale } \\
\text { (iv) Structured Interview } \\
\text { (v) PART-O } \\
\text { (vi) Modified Caregiver } \\
\text { Appraisal Scale } \\
\text { (caregiving mastery } \\
\text { subscale) } \\
\text { (vii) Caregiver } \\
\text { Knowledge \& Skill } \\
\text { Acquisition (researcher- } \\
\text { developed items) } \\
\text { (viii) Brief COPE }\end{array}$ & $\begin{array}{l}\text { Length: 5-months, with a } \\
\text { 6-month follow-up. } \\
\text { Intervention: ( } n=77) \\
\text { self-guided web-based } \\
\text { caregiving and TBI- } \\
\text { specific online modules, } \\
\text { plus concurrent biweekly } \\
\text { telephone calls to discuss } \\
\text { problems and solutions. } \\
\text { Modules were not } \\
\text { presented in a specific } \\
\text { order, rather caregivers } \\
\text { were directed to relevant } \\
\text { modules during telephone } \\
\text { calls as indicated by their } \\
\text { answers to a brief } \\
\text { interview at the onset of } \\
\text { the call. } \\
\text { Usual care: }(n=76) \\
\text { standard care. }\end{array}$ & $\begin{array}{l}\text { Caregivers in the } \\
\text { intervention group } \\
\text { showed significantly } \\
\text { higher quality of life and } \\
\text { emotional well-being. } \\
\text { They also showed } \\
\text { significantly more active } \\
\text { coping strategies and less } \\
\text { emotional venting coping } \\
\text { styles at follow-up. } \\
\text { Caregivers also tended to } \\
\text { report more support from } \\
\text { others, feeling more } \\
\text { competent at obtaining } \\
\text { information from medical } \\
\text { professionals, and taking } \\
\text { care of themselves than } \\
\text { usual care. }\end{array}$ \\
\hline
\end{tabular}

Length: 6 months.

Intervention: $(n=124$

dyads) access to a web site with written and audiovisual selfmanagement strategies, a bulletin board, and other resources; visits with a recipient dyads

Family caregivers of persons with advanced cancer (i) CES-D

(ii) Caregiver Quality of Life Index-Cancer Scale

\section{$[67]^{*}$} (intervention only)
(insite, in-person

Telephone, asynchronous care coordinator every 2 months during a

physician visit; and telephone follow-up every 2 weeks. Participants also received visits from a care coordinator.

Usual care: $(n=100$

dyads) standard care.

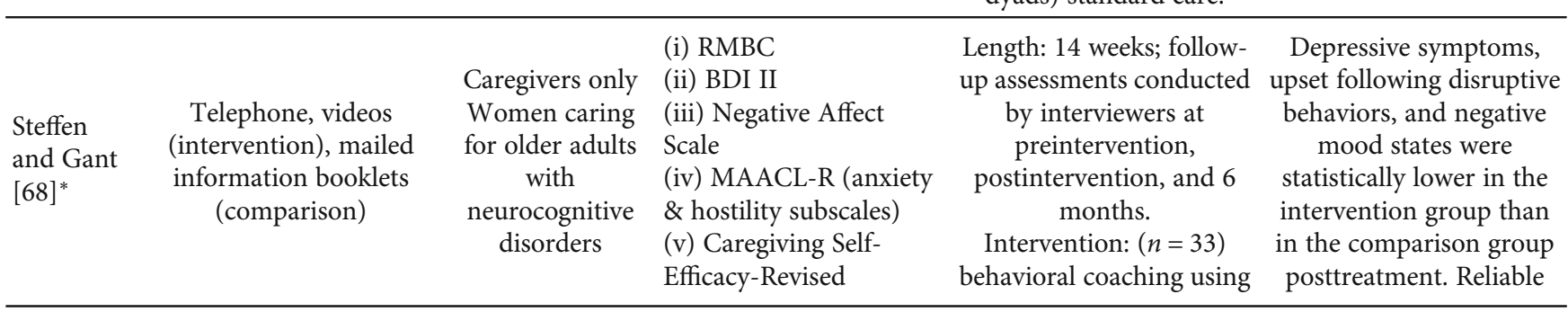

Caregiver stress and depression decreased significantly at 6 months for those in the intervention group. 
TABLE 5: Continued.

\begin{tabular}{|c|c|c|c|c|c|}
\hline \multicolumn{6}{|c|}{ Combined telephone and web interventions $(n=10)$} \\
\hline Authors & & Caregiver group & Study measures & Intervention description & Findings \\
\hline & & & $\begin{array}{l}\text { (obtaining respite \& } \\
\text { responding to disruptive } \\
\text { behaviors subscales) }\end{array}$ & $\begin{array}{c}\text { online video instructional } \\
\text { materials, workbook, and } \\
12 \text { telephone coaching } \\
\text { sessions ( } 10 \text { weekly, last } 2 \\
\text { biweekly) in behavioral } \\
\text { management, pleasant } \\
\text { events scheduling, and } \\
\text { relaxation. } \\
\text { Attention control: }(n=41) \\
\text { basic education guide and } \\
\text { telephone support in } 7 \\
\text { bimonthly calls. }\end{array}$ & $\begin{array}{l}\text { change index analyses for } \\
\text { BDI II scores favored the } \\
\text { intervention. Caregiving } \\
\text { self-efficacy scores for } \\
\text { obtaining respite and for } \\
\text { managing patient } \\
\text { behavioral disturbances } \\
\text { were significantly higher. }\end{array}$ \\
\hline $\begin{array}{l}\text { Williams } \\
\text { et al. } \\
{[69]^{*}}\end{array}$ & $\begin{array}{l}\text { Stand-alone video series, } \\
\text { telephone }\end{array}$ & $\begin{array}{l}\text { Caregivers only } \\
\text { Family } \\
\text { caregivers of } \\
\text { older adults with } \\
\text { Alzheimer's } \\
\text { disease or } \\
\text { related dementia }\end{array}$ & $\begin{array}{l}\text { (i) Perceived Stress Scale } \\
\text { (ii) State Trait Anxiety } \\
\text { Inventory } \\
\text { (iii) State-Trait Anger } \\
\text { Inventory } \\
\text { (iv) CES-D } \\
\text { (v) Cook-Medley } \\
\text { Hostility Scale } \\
\text { (vi) Caregiving Self- } \\
\text { Efficacy-Revised } \\
\text { (vii) Pittsburgh Sleep } \\
\text { Quality Index } \\
\text { (viii) Blood Pressure } \\
\text { (ix) Heart Rate } \\
\text { (x) Salivary Cortisol } \\
\text { Levels }\end{array}$ & $\begin{array}{l}\text { Length: } 5 \text { weeks, with } \\
\text { follow-up } 41 / 2 \text { months } \\
\text { postintervention. } \\
\text { Intervention: }(n=59) \\
\text { online video-based } \\
\text { modules with coping } \\
\text { skills training related to } \\
\text { dementia caregiving, with } \\
\text { an accompanying } \\
\text { workbook, and } 5 \text { weekly } \\
\text { telephone coaching } \\
\text { sessions. } \\
\text { Wait list control: }(n=57) \\
\text { received the intervention } \\
\text { following the study. }\end{array}$ & $\begin{array}{l}\text { Outcomes for the } \\
\text { intervention and wait list } \\
\text { control groups } \\
\text { significantly differed on } \\
\text { depression, perceived } \\
\text { stress, and blood pressure. } \\
\text { Differences in the } \\
\text { predicted direction were } \\
\text { sustained through follow- } \\
\text { up assessments at } 5 \\
\text { months postintervention, } \\
\text { but interpretability of } \\
\text { these findings is limited } \\
\text { by baseline differences in } \\
\text { some variables. }\end{array}$ \\
\hline
\end{tabular}

Study reported significant improvement in at least one target outcome in the intervention group as compared to the control/comparison group. MARWIT: Marwit-Meuser Caregiver Grief Inventory-Short Form; CSI: Caregiver Strain Index; CQoLI-R: Caregiver Quality of Life Index-Revised; GAD-7: Generalized Anxiety Dixorder-7; TBI: traumatic brain injury; BSI: Brief Symptom Inventory; PART-O: Participation Assessment with Recombined Tools-Objective; RMBC: Revised Memory \& Behavior Problems Checklist; BDI II: Beck Depression Inventory II; MAACL-R: Multiple Affect Adjective Check List-Revised; ZBI: Zarit Burden Interview; SAI: State Anxiety Inventory; PHQ: Patient Health Questionnaire; BCOS: Bakas Caregiving Outcomes Scale; HADS: Hospital Anxiety and Depression Scale; RMBPC: Revised Memory and Behavioral Problem Checklist.

57 included articles, only 16 (28\%) were caregiver-care recipient dyad studies. The majority of intervention studies $(n=32,56 \%)$ centered on family caregivers of older adults with neurological conditions, such as dementia and stroke. A substantially smaller percentage of studies focused on interventions for caregivers of persons with cancer $(n=6,11 \%)$ and caregivers of children, adolescents, and young adults with chronic health conditions $(n=6,11 \%)$. Only a few intervention studies targeted caregivers of persons with heart failure $(n=2,4 \%)$ and persons receiving hospice or palliative care $(n=2,4 \%)$.

Of the 57 included studies, $58 \%(n=33)$ were telephonemediated, 25\% $(n=14)$ used web technologies, and the remainder $(n=10,17 \%)$ used a combination of telephone and web modalities (Tables 3-5). Last, the 57 included studies were published in 42 different journals, primarily psychological and medical in nature. The randomized controlled trials were conducted in nine different countries, with the United States accounting for $80 \%$ of publications.

3.1.2. Intervention Components. Of the 57 studies, the majority of interventions $(n=37,65 \%)$ were $\leq$ six months long, included participant follow-up for $\leq$ six months $(n=17$, $30 \%)$, and did not incorporate booster sessions $(n=53$,
93\%). Furthermore, most studies ( $n=47,82 \%)$ did not collect postintervention data. Across the 57 studies, interventions included at least one of five different components, including skills training (group, individual, or both), psychoeducational and resource materials, self-monitoring/tracking, reminders, and counseling (group or individual). Skills training was conducted most often $(n=43,75 \%)$ either individually $(n=32$, $56 \%)$, in a group $(n=9,16 \%)$, or using a combination of individual and group training $(n=2,4 \%)$. Topics covered in the skills-building sessions varied across telehealth modalities and included training on effective communication, diseasespecific caregiving skills, care recipient safety, social skills, and problem-solving. Psychoeducational and resources materials also were commonly used $(n=40,70 \%)$ to supplement intervention components and covered similar topics across modalities (e.g., problem-solving, stress management, and coping skills). Other less frequently used strategies consisted of individual $(n=8,14 \%)$ or group $(n=7,12 \%)$ counseling and the use of self-monitoring/tracking $(n=14,25 \%)$ and reminders $(n=4,7 \%)$ (Table 6$)$.

3.1.3. Outcomes. Forty-two of 57 studies (74\%) reported significantly greater improvement on at least one target 


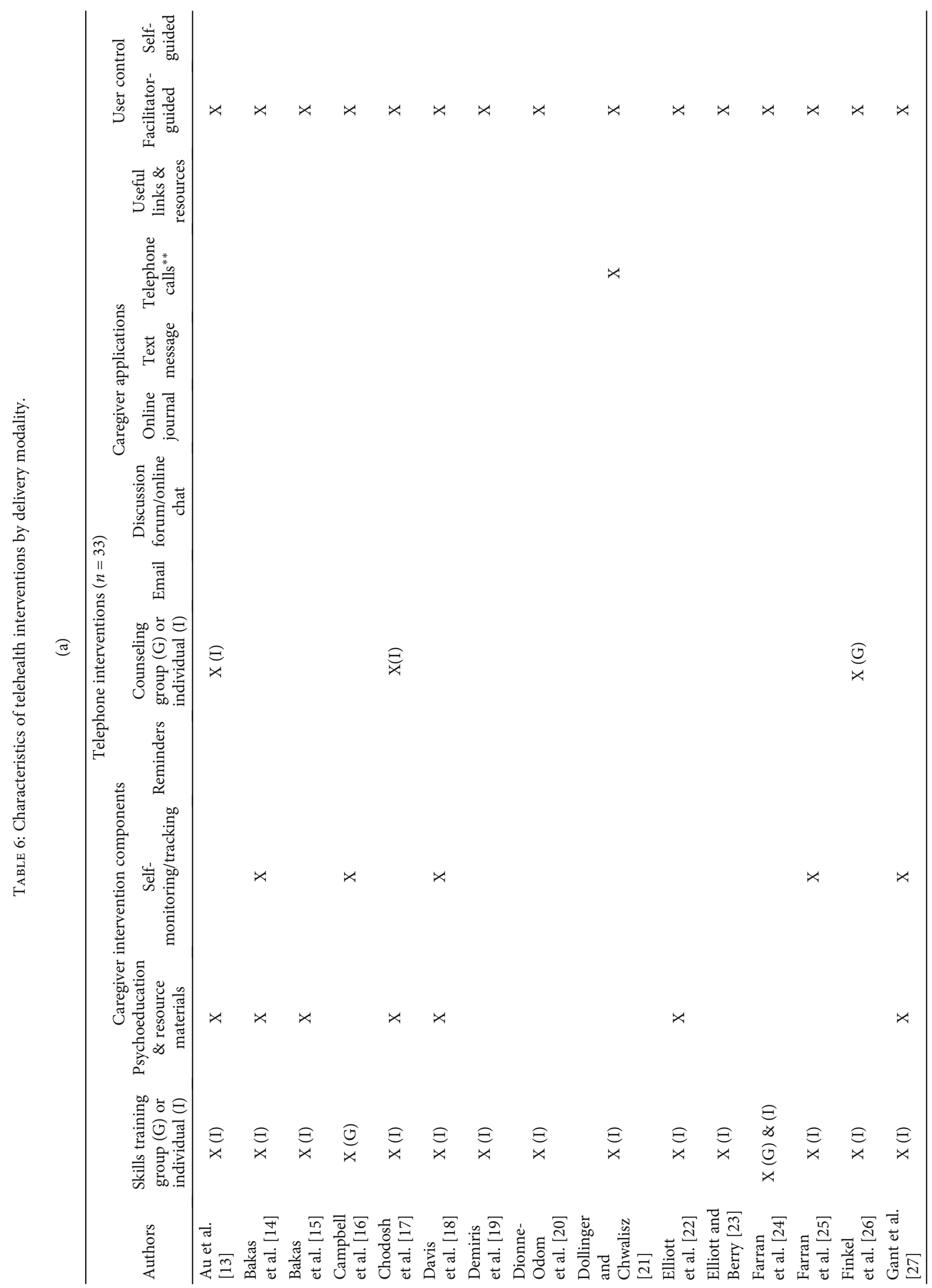




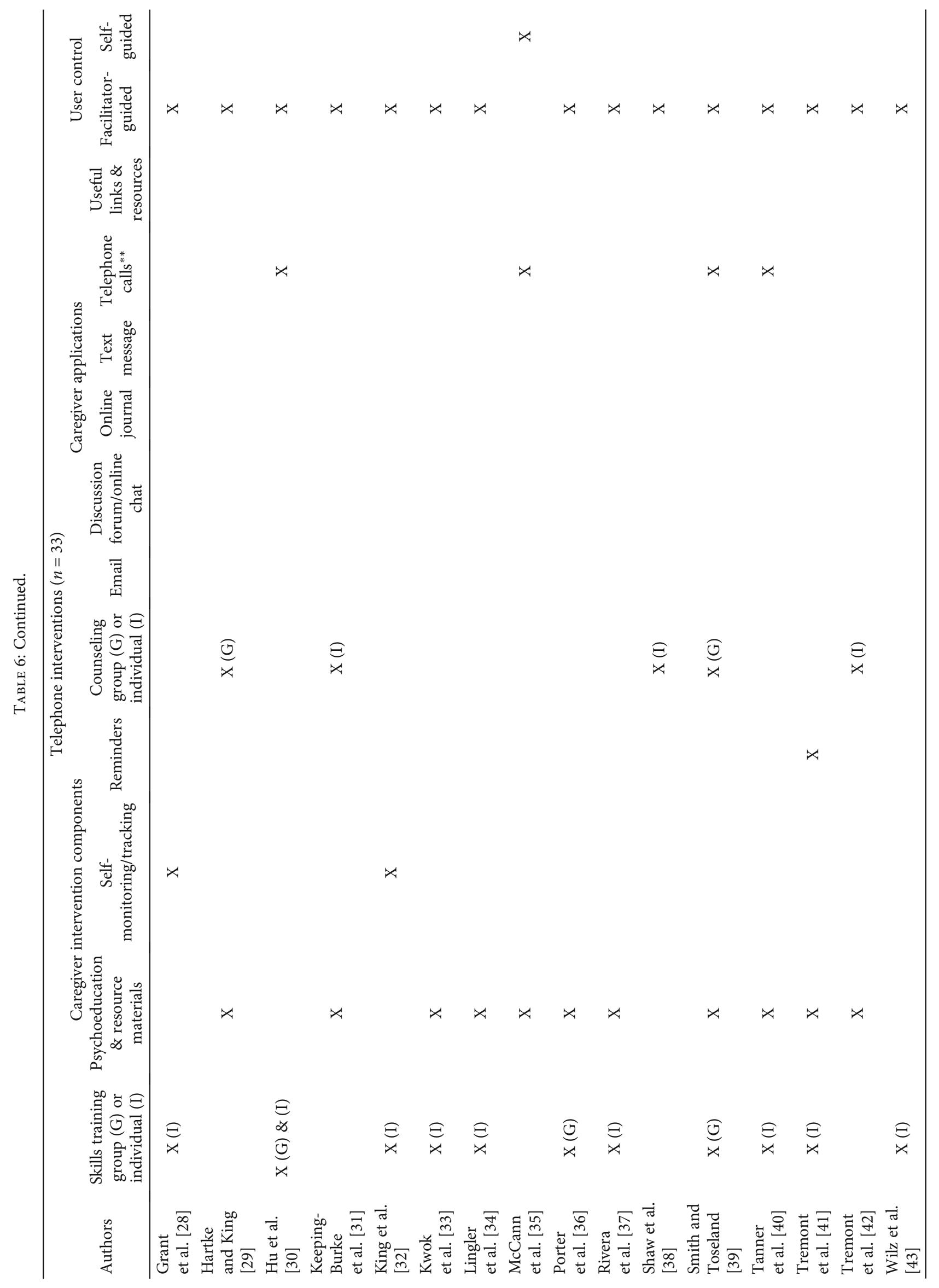




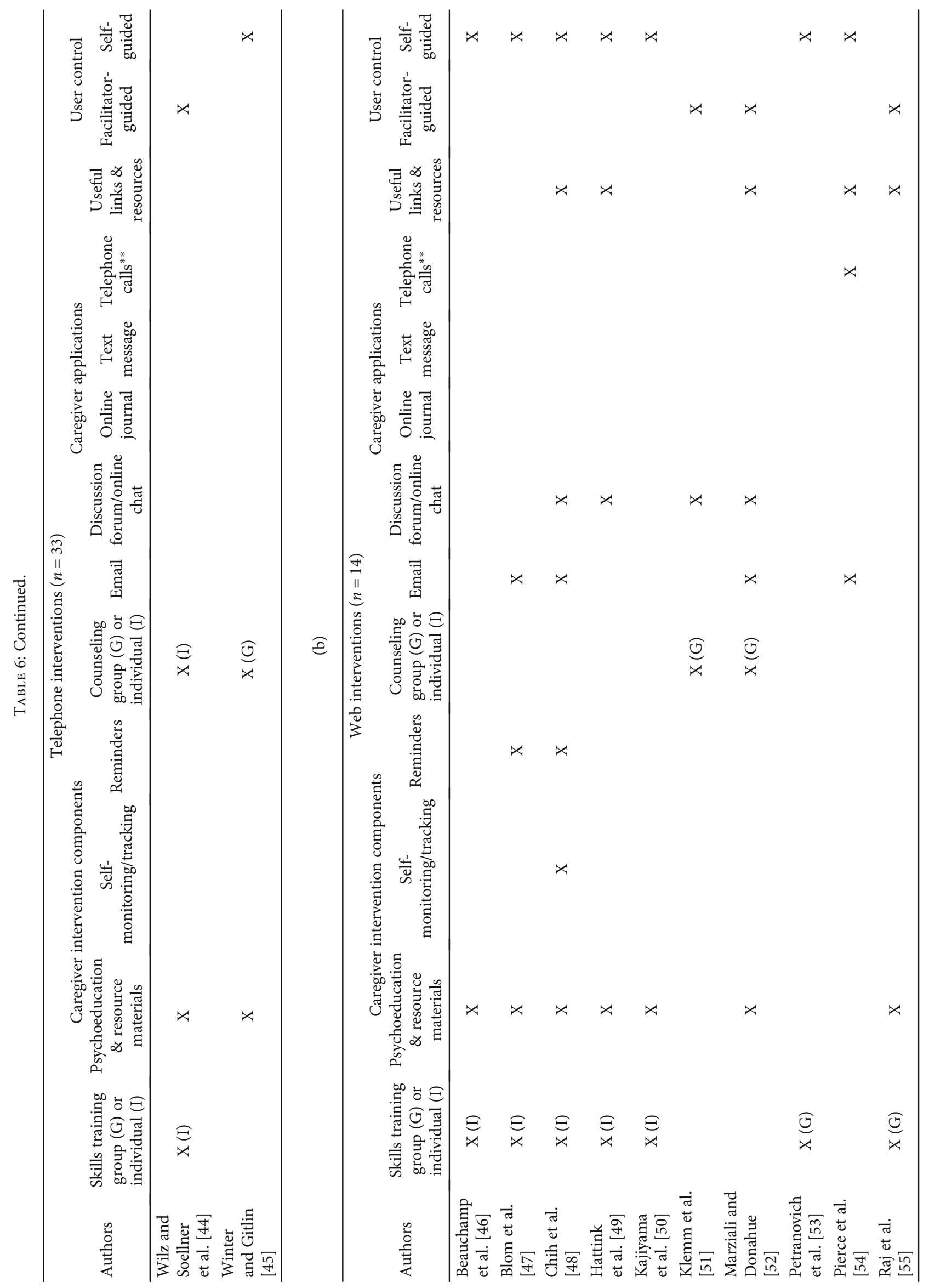




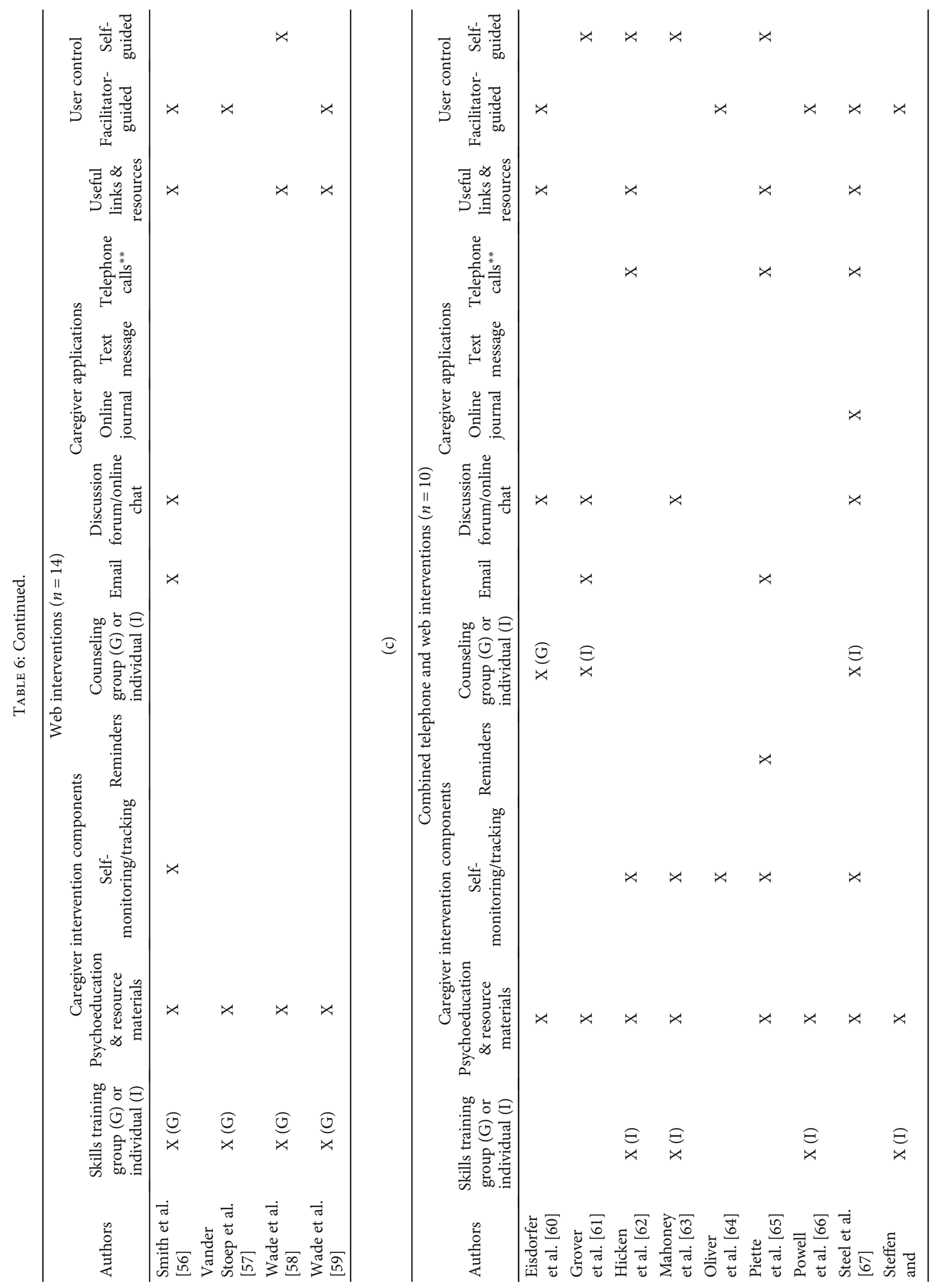




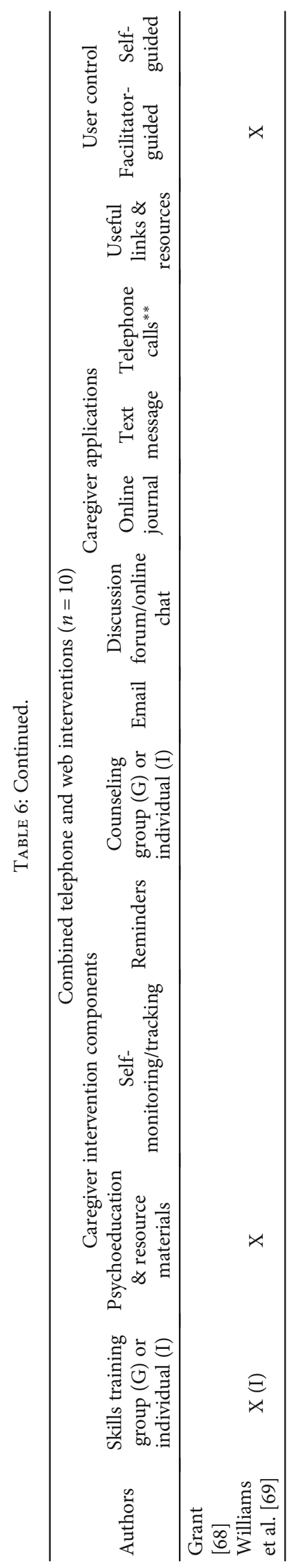


outcome for caregivers participating in the intervention versus those in the other groups. Fifteen of the 57 studies (26\%) reported nonsignificant findings on target outcomes (Tables 3-5). Significant differential improvement in psychological well-being was noted in the intervention conditions for the majority of studies $(n=36,63 \%)$, followed by enhanced health and physiological functioning $(n=8,14 \%)$, as well as improved caregiving skills $(n=8,14 \%)$. Less common findings included significant improvements in social functioning $(n=6,11 \%)$, quality of life $(n=5,9 \%)$, and problem-solving/goal setting $(n=3,5 \%)$ for the intervention groups as compared to comparison/control group counterparts. Fifteen of the 57 (26\%) included studies did not show significant improvement in caregiver outcomes following intervention compared to the comparison/control groups (Tables 3-5).

3.1.4. Applications and User Control. Across the 57 studies, 12 (21\%) included useful links and resources for caregivers to supplement the intervention, such as psychological and physical symptom inventories [48], caregiving tip sheets [54], online educational videos/modules $[54,56]$, and links to disease-specific websites [58]. Discussion forums/online chats were used in nine studies $(16 \%)$ to foster communication and peer support $[11,49,51,52,56,60,61,63,67]$. Telephone calls independent of the intervention also were used in nine studies $(16 \%)$ to provide support $[21,39]$ and to facilitate consultation and follow-up [30, 35, 40, 54, 62, 65, 67]. Alternately, email was used in seven studies (12\%) to maintain communication with participants $[48,52,54,56,61$, 65] and to distribute materials to caregivers [47]. Only one study (2\%) included online journaling to facilitate caregivers' documentation of caregiving issues and care recipients' health status [67] (Table 6).

\subsection{Telephone Interventions}

3.2.1. Samples. Of the 33 telephone intervention studies, 23 (70\%) included caregivers only, whereas 10 (30\%) engaged both caregivers and care recipients in dyadic intervention. Sixteen studies (48\%) included caregivers of older adults with progressive dementia, followed by caregivers of individuals with stroke $(n=4,12 \%)$ and cancer $(n=4,12 \%)$. Caregivers of individuals with unspecified chronic conditions $(n=3,9 \%)$, neurological injuries (i.e., spinal cord and traumatic brain injury; $n=2,6 \%)$, cardiovascular conditions $(n=2,6 \%)$, and depression $(n=1,3 \%)$, as well as adults in hospice care $(n=1,3 \%)$, were less represented. Fifteen studies (45\%) included more than 100 participants, 13 studies (39\%) included 50-100 participants, and five studies (15\%) included 10-50 participants (Table 3).

3.2.2. Intervention Components. Among the five types of components implemented in the 33 caregiver telephone interventions, skills training procedures $(n=27,82 \%)$ were deployed most often, the bulk of which were delivered to individual caregivers $(n=22,67 \%)$, followed by the use of group format $(n=3,9 \%)$ or a combination of group and individual training $(n=2,6 \%)$. The foci of skills training included communication enhancement techniques, disease- specific caregiving methods, monitoring and management of care recipient's physical and psychological well-being, care recipient safety, and fostering caregiving self-care activities. A variety of materials were used to bolster skills training, including print materials (e.g., pamphlets, tip sheets [14, $15]$, and caregiver workbooks $[27,38]$ ) and video modules/DVDs $[27,33]$. Psychoeducational and resource information also were commonly used $(n=20,61 \%)$, primarily in conjunction with problem-solving strategies, stress management, relaxation, and coping skills techniques. Group or individual supportive counseling $(n=10,30 \%)$, caregiver self-monitoring/tracking $\quad(n=7,21 \%), \quad$ and reminders $(n=1,3 \%)$ were incorporated less frequently in the telephone interventions (Table 6).

3.2.3. Outcomes. Twenty-one of 33 telephone studies (64\%) reported statistically significant caregiver improvements on target outcomes in the intervention conditions compared to little or no change in comparison/control conditions. Of the 33 telephone studies, 12 (36\%) reported nonsignificant intervention effects on target outcomes (Table 3). Differential posttreatment gains were found across the following sets of variables in descending order of frequency: (a) psychological well-being (e.g., decreased depression and anxiety; improved coping) ( $n=16,48 \%)$, (b) enhanced health and physiological functioning (increased physical activity, decreased blood pressure $\quad(n=6,18 \%)$, (c) improved caregiving skills $(n=4,12 \%)$, (d) increased social functioning $(n=4,12 \%)$, (e) enhanced problem-solving/goal setting $(n=3,9 \%)$, and (f) improved quality of life $(n=3,9 \%)$. In contrast, 12 studies (36\%) did not obtain significantly greater gains in caregiver outcomes for the intervention groups versus the comparison/control groups (Table 3).

3.2.4. Applications and User Control. Five studies (15\%) included telephone calls independent of the intervention to provide real-time support [21, 39], consultation, and follow-up [30, 35, 40]. Ninety-four percent of telephonemediated studies $(n=31)$ were facilitator-guided, whereas only $6 \%(n=2)$ used a self-guided approach (Table 6).

\subsection{Web Interventions}

3.3.1. Samples. Of the 14 web studies, nine (64\%) included family caregivers only, focusing on caregivers of adults with dementia $(n=4,44 \%)$, children/adolescents with traumatic brain injury $(n=2,22 \%)$, adults with neurodegenerative disorders $(n=1,11 \%)$, stroke $(n=1,11 \%)$, and unspecified chronic illness $(n=1,11 \%)$. Five studies (36\%) engaged both caregiver and care recipient dyads and involved caregivers of children/adolescents with traumatic brain injury $(n=2,40 \%)$ and attention deficit-hyperactivity disorder $(n=1,20 \%)$, as well as caregivers of adults with advanced stage cancer $(n=1,20 \%)$ and stroke $(n=1,20 \%)$. Seven studies $(50 \%)$ recruited over 100 participants, three studies $(21 \%)$ had 50 100 participants, and four studies (29\%) included 10-50 participants (Table 4).

3.3.2. Intervention Components. Skills training (group or individual), psychoeducational and resource materials, group 
counseling, self-monitoring/tracking, and reminders were the primary intervention components used in the web interventions. Skills training $(n=11,79 \%)$ consisted of both group $(n=6,43 \%)$ and individual formats $(n=5,38 \%)$ and covered topics such as social skills enhancement (e.g., arranging care assistance [47]), assertiveness, disease-specific caregiving skills $[48,56]$, and effective communication with care recipients and healthcare professionals [53]. Psychoeducational and resource materials $(n=11,79 \%)$ included information about coping skills, problem-solving, relaxation techniques, stress management, and/or cognitive behavioral training/restructuring. Self-monitoring/tracking $(n=2,14 \%$ ), reminders $(n=2,14 \%)$, and group counseling $(n=2,14 \%$ ) were used infrequently in the web studies (Table 6).

3.3.3. Outcomes. Eleven of 14 (79\%) web studies reported significant improvements on target outcomes in the intervention groups as compared to little or no change in the comparison/control groups. Three (21\%) of 14 web studies reported nonsignificant intervention effects on target outcomes (Table 4). Differential increases in psychological well-being (e.g., decreases in depression, anxiety, and stress) were the predominant outcomes in the intervention arms across the 11 studies (79\%). Other significant outcomes were obtained for caregiving skills (i.e., improved caregiving selfefficacy; $n=1,7 \%$ ) and quality of life (i.e., increased positive appraisals of caregiving; $n=1,7 \%$; improved quality of life; $n=1,7 \%$ ) (Table 4).

3.3.4. Applications and Use Control. Eight studies (57\%) provided useful web links and resources (e.g., online educational materials, tip sheets [54] and asynchronous modules [55]) to supplement the intervention. Email was incorporated in five studies $(36 \%)$ to enhance communication with the research team $[48,52,54,56]$ and to provide materials to participants [47]. Five studies (36\%) used discussion forums/online chat to facilitate communication and to encourage peer support $[48,49,51,52,56]$. Telephone calls independent of the intervention were used to follow up with participants in one study (7\% [54]). Eight of the web interventions were self-guided $(57 \%)$ and six (43\%) were facilitator-guided (Table 6).

\subsection{Combined Telephone and Web Interventions}

3.4.1. Samples. Of the 10 combined telephone and web studies, 9 (90\%) recruited family caregivers only and 1 (10\%) involved both caregivers and care recipients in dyadic intervention. These studies included caregivers of adults with a variety of chronic medical conditions, including progressive dementia $(n=5,50 \%)$, heart failure $(n=1,10 \%)$, traumatic brain injury $(n=1,10 \%)$, cancer $(n=1,10 \%)$, anorexia nervosa $(n=1,10 \%)$, and unspecified older individuals receiving hospice care $(n=1,10 \%)$. Seven studies $(70 \%)$ recruited over 100 participants and three studies $(30 \%)$ included between 50 and 100 participants (Table 5).

3.4.2. Intervention Components. The primary intervention components included psychoeducational and resource materials, individual skills training, self-monitoring/tracking, counseling (group or individual), and reminders. Psychoedu- cational and resource materials, providing information about problem-solving, modification of cognitions and behavior (e.g., goal setting and attainment [61]), stress management [68], and coping skills [69] were the predominant intervention components across the combined telephone and web studies $(n=9,90 \%)$. Five studies (50\%) incorporated individual skills training focusing on disease-specific caregiving strategies (e.g., video vignettes on dementia progression [62]), problem-specific response skills [66], and event scheduling/time management $[67,68]$. Self-monitoring/tracking $(n=5,50 \%)$ was used to follow caregivers' progress and completion of intervention-related components. Strategies, such as individual $(n=2,20 \%)$ (e.g., weekly therapist guidance by phone/email [61]) and group $(n=1,10 \%)$ counseling (e.g., discussion of caregiver problems and identification of helpful resources [60]), as well as reminders $(n=1,10 \%)$, were used infrequently in the combined interventions (Table 4).

3.4.3. Outcomes. All ten combined telephone and web studies (100\%) reported significant caregiver improvements on target outcomes in the intervention conditions as compared to little or no change in the comparison/control conditions (Table 5). Improvements in psychological well-being (e.g., decreased depression and stress; increased coping) in the intervention conditions were reported across 9 of 10 studies (90\%). Enhanced social/family functioning (e.g., increased perceived social support) also was found among intervention participants in two studies (20\%). Significant gains in caregiving skills (e.g., increased caregiver self-efficacy) were reported by intervention caregivers in two studies (20\%). Similarly, greater improvement in well-being (e.g., increased participation in self-care activities) also was obtained in the intervention conditions as compared to comparison/controls counterparts in one study (10\%). Finally, improvement in quality of life was found among intervention participants for 1 of 10 studies (10\%) (Table 5).

3.4.4. Applications and Use Control. Discussion forums/online chat were used in four studies (40\%) to foster communication and provide support $[60,61,63,67]$. Four studies (40\%) provided useful web links and resources to supplement the intervention $[60,62,65,67]$. Three studies (30\%) included telephone calls with caregivers that were independent of the intervention $[62,65,67]$, whereas two studies (20\%) used email to communicate with caregivers $[61,65]$. Online journaling was used in one study $(10 \%)$ to facilitate documentation of psychological and physical challenges related to caregiving and care recipients' health [67]. Six studies $(60 \%)$ were facilitator-guided and four (40\%) were self-guided (Table 6).

\section{Discussion}

In examining the descriptive findings across modalities, telephone delivery was the most used approach. One possible explanation for the disproportionate use of telephone across studies lies in the demographic characteristics of caregivers of persons with dementia and stroke, who were more likely to 
be older adults and in turn, slower adopters of web technologies. In contrast, caregivers of children/adolescents were generally younger parents who incorporated web technologies into their daily lives and thus more likely to participate in web intervention. Of the six studies with caregivers of children, adolescents, and young adults, web modalities were used most often $(n=5,83 \%)$, followed by combined telephone and web modalities $(n=1,17 \%)$.

Next, over $70 \%$ of included studies focused exclusively on caregiver intervention rather than the caregiver-care recipient dyad. This decision may have been predicated by the diminished capacity of the care recipient to benefit from intervention, logistical issues, and limited exposure to dyadic treatment. First, over $50 \%$ of care recipients across the 57 studies were older adults with neurological disorders. Cognitive deficits, such as short-term memory loss and difficulties with verbal comprehension and expression, may pose obstacles in care recipient engagement in telehealth intervention $[2,11]$. Second, logistic difficulties may have led to limited implementation of interventions involving both caregivers and care recipients. For example, organizing dyadic sessions may be problematic due to scheduling conflicts, competing job demands and collateral family obligations. Last, dyadic intervention requires specialized therapeutic skills many telehealth providers may not possess.

Regarding caregiver intervention strategies, skills training was used in $75 \%$ of studies across modalities. In contrast to previous research [11], both telephone $(n=27,81 \%)$ and web approaches $(n=11,78 \%)$ showed similar utilization rates in deploying skills training strategies. Prior research [11] reports disproportionately lower integration of skills training approaches in web interventions as compared to telephone modalities.

The format and methods of delivery of psychoeducational and resource materials varied considerably across modalities. In telephone interventions, caregivers received information booklets, manuals, or videos through the mail $[14,21,27]$. In web and combined telephone and web modalities, psychoeducation and resource materials were delivered online using modules, interactive platforms, and video vignettes $[47,48,62]$. Relatively high utilization rates of psychoeducation and resource information were noted across telephone, web, and combined telephone and web interventions (i.e., $61 \%, 79 \%$, and $90 \%$, respectively). This pattern was similar to that previously reported [11]. Overall, the technologies used in the interventions included in this review were basic, easy-to-use, and low-cost, such as telephone, videoconferencing [51, 58], DVD, web-based modules [33, 46, $50,62]$, and interactive web-based platforms $[47,61]$. However, one intervention incorporated a computer-mediated interactive voice response system [63] that required more sophisticated programming than other technologies highlighted in this review.

Self-monitoring/tracking was used infrequently across all modalities $(n=14,25 \%)$. Limited incorporation of this component was difficult to interpret, particularly in light of its importance in guiding judgments about effectiveness of the treatment process. Furthermore, a more pronounced pattern of disuse was found for reminders. Only 7 of 57 studies included reminders to enhance attendance and adherence to intervention. A plausible explanation may be self-monitoring, and tracking systems were used in these studies, but not reported.

Next, caregiver applications were integrated into intervention for 21 of 57 studies (37\%). Of the telephone interventions, only the independent phone call application was incorporated during intervention. However, the utilization rate was low (15\%). Surprisingly, none of the telephone studies used text messaging. This finding may have its origin in lower adoption rates of digital technologies and/or use of text-based communication among caregivers of persons with dementia and stroke, a large proportion of whom were older adults.

In contrast, four applications were used in the web interventions and five with the combined telephone and web interventions (Table 6). Except for online journaling [67], both web and combined telephone and web interventions adopted similar caregiver applications. Useful links and resources were used in $57 \%$ of web applications and $40 \%$ of combined telephone and web interventions. Discussion forums were implemented in web and combined telephone and web interventions at similar rates (36\% and 40\%), respectively. In contrast, email was used more often in the web studies (36\%) compared to combined telephone and web modalities (20\%). This finding suggests telephone may have replaced email use in the latter telecommunication approach.

Last, a discrepant pattern for user control was noted across the three intervention modalities. Ninety-four percent of telephone and $60 \%$ of combined telephone and web interventions were facilitator-guided. In contrast, most web interventions (57\%) were self-guided. Web technologies may be more appropriate for caregivers who are technologically savvy and require less guidance in assimilating information acquired through this modality.

Regarding intervention outcomes, significant improvements in at least one target caregiver outcome were found in $74 \%$ of the studies across all three modalities. Consistent with prior research [2], improvement in caregiver psychological well-being was the most frequently reported outcome (48\%) in the telephone interventions. Significant improvements in psychological well-being also were obtained in the web $(79 \%)$ and combined telephone and web interventions (90\%), corroborating prior findings [11]. However, it is difficult to interpret the underlying reasons for increasing percentages of positive outcomes in psychological well-being across categories. This issue requires investigation in future studies.

Next, a discrepant pattern of results was found for physiological outcomes. Statistically significant improvements in health and physiological functioning were evidenced in both telephone (18\%) and combined telephone and web methods $(10 \%)$, but little or no change on these variables was found in the web interventions. This discrepancy may have been due to the self-guided nature of web modalities. In the absence of facilitator feedback, tailoring of intervention to bolster health and physiological functioning was precluded.

While this review provides an excellent summary of telehealth research through January 2017, this review does not 
capture more recent telehealth studies. However, since our review, there have been no published systemic reviews of telehealth interventions for caregivers of the chronically ill which encompasses a variety of study populations, interventions, and outcomes, as does this review. Further, although the current systematic review consisted of a variety of telehealth interventions, four major limitations were noted in the included studies. First, the overall pattern of intervention outcomes may have been skewed by the incorporation of telephone in two of three intervention categories. Although telecommunication technologies are increasing in popularity, a large population of caregivers continues to face considerable barriers in accessing interventions using these modalities, particularly older caregivers and those who reside rural geographical locations. Unmet technology training needs, high cost of equipment, and barriers in gaining access to Internet service, especially among older adult caregivers, may have accounted for the disproportionate use of telephone in caregiver telehealth studies [70]. Second, web and combined telephone and web interventions were conducted exclusively with caregivers of children, adolescents, and young adults. Telephone interventions were not performed with this caregiver population. Therefore, our knowledge of the efficacy of telephone interventions across the age continuum was restricted in this review. Third, although telehealth modalities hold considerable promise in increasing access to hard-to-reach populations, the majority of studies in this review did not specify caregivers' and care recipients' primary area of residence (e.g., rural or urban). This shortcoming limited evaluation of the impact of geographic location on treatment outcomes. Last, a large proportion of studies incorporated interventions to enhance caregiving and selfcare skills. However, the impact of these activities on psychological functioning and health status as well as their level of implementation was not measured.

4.1. Research and Practice Implications. The overall findings of this review provided considerable support for the efficacy of telehealth interventions across a variety of psychosocial and emotional outcomes in diverse populations. A major strength of the current systematic review was the selection of studies using randomized controlled designs. This decision was predicated not only on the need for increased rigor in drawing causal conclusions but also on the growing use of telehealth interventions in caregiver research $[2,11]$.

Despite these encouraging developments, only a limited number of studies compared the effects of telehealth intervention versus an in-person comparator. For example, Davis et al. [18] compared the effects between telephone caregiver coping skills training and in-person intervention using the same protocol on changes in psychosocial functioning for dementia caregivers. The investigators found positive and equivalent gains in caregiver burden and distress at three months across both treatment conditions. In contrast, none of the web or combined telephone and web studies tested the differential impact of these modalities against similar in-person interventions. Thus, more research is needed to evaluate the efficacy of telehealth modalities versus in- person intervention delivery. Further, research is needed to test the equivalence or noninferiority of the effects of telecommunicated intervention versus traditional in-person interventions. The findings of such investigations will provide valuable information about the strengths and limitations of deploying specific telehealth delivery methods across different caregiver populations, caregiving challenges, and geographic and socioeconomic conditions.

This review found that telehealth modalities can be used successfully in delivering a variety of skills training and psychoeducational interventions for family caregivers. With recent advances in telehealth technologies, clinicians can conduct a wide variety of psychosocial and behavioral interventions that support caregivers' emotional functioning regardless of location and proximity to healthcare providers. Clinicians also have access to a wide array of online resources, videos, interactive modules, and other healthpromoting technologies to enhance caregivers' skills in stress management, emotional well-being, and their health status. Although useful for all caregivers, telehealth modalities may be particularly beneficial in reaching rural caregivers, who are less likely to attend caregiving workshops due to financial or transportation issues.

Furthermore, telehealth intervention offers an effective method for promoting increased self-care in distressed caregivers. In a study by Piette et al. [65], caregivers received weekly, automated support calls with the option of obtaining guidance about care recipients' problems from an interdisciplinary team coupled with email suggestions for enhancing caregiver's self-care. Findings showed that caregivers who received the support calls reported significantly less caregiving strain compared to caregivers in the control conditions. Telehealth intervention holds considerable promise in addressing efficiently and effectively both caregiving challenges and the self-care concerns of family caregivers where and when assistance is needed. Therefore, clinicians should consider incorporating telehealth modalities for caregiver correspondence to assess emotional health and provide an avenue for caregivers to discuss support needs between scheduled healthcare visits.

\section{Conclusion}

The advancement and increased utilization of telehealth technologies offer unique opportunities to improve caregiver emotional functioning, health status, and caregiving skills. Findings of this review suggest that telehealth modalities are effective tools in delivering a variety of caregiver interventions, with significant improvements on several target caregiver outcomes across studies. Telehealth has been used most often to deliver skills training strategies to improve caregiver psychological well-being and enhance caregiver support. However, further research is needed to evaluate the efficacy of telehealth interventions in improving caregiving skills and caregiver self-efficacy, as well as caregiver health outcomes. Likewise, future studies need to examine the benefits of telehealth interventions with underserved, rural-residing caregiver populations. 


\section{Data Availability}

For information regarding the data supporting the results of this study, please email lgraven@fsu.edu.

\section{Conflicts of Interest}

The authors have no conflicts of interest to declare.

\section{References}

[1] National Alliance for Caregiving (NAC) and American Association for Retired Person (AARP) Policy Institute, "Caregiving in the U.S.," 2015, https://www.aarp.org/content/dam/ aarp/ppi/2015/caregiving-in-the-united-states-2015-reportrevised.pdf/.

[2] R. L. Glueckauf and L. T. Noël, "Telehealth and family caregiving: developments in research, education, policy, and practice," in Education and Support Programs for Caregivers, R. W. Toseland, D. H. Haigler, and D. J. Monahan, Eds., pp. 85-105, Springer, New York, 2011.

[3] Alzheimer's Association, "Alzheimer's disease facts and figures," Alzheimer's \& Dementia, vol. 14, pp. 367-429, 2018.

[4] B. A. Wells, R. L. Glueckauf, D. Bernabe et al., "African American dementia caregiver problem inventory: descriptive analysis and initial psychometric evaluation," Rehabilitation Psychology, vol. 62, no. 1, pp. 25-35, 2017.

[5] K. J. Joling, H. W. van Marwijk, A. E. Veldhuijzen et al., “The two-year incidence of depression and anxiety disorders in spousal caregivers of persons with dementia: who is at the greatest risk?," The American Journal of Geriatric Psychiatry, vol. 23, no. 3, pp. 293-303, 2015.

[6] House of Representatives (111th Congress), "National Alzheimer's Project Act of 2010. S. 3036," 2010, https://www .govtrack.us/congress/bills/111/hr4689/text/.

[7] United States Department of Veteran Affairs, "REACH VA Program," 2019, https://www.caregiver.va.gov/REACH_VA_ Program.asp/.

[8] Rosalyn Carter Institute for Caregiving, "Operation family caregiver," 2019, http://www.operationfamilycaregiver.org/.

[9] D. M. Ehde, T. M. Dillworth, and J. A. Turner, "Cognitivebehavioral therapy for individuals with chronic pain: efficacy, innovations, and directions for research," The American Psychologist, vol. 69, no. 2, pp. 153-166, 2014.

[10] R. L. Glueckauf, W. S. Davis, F. Willis et al., "Telephone-based, cognitive-behavioral therapy for African American dementia caregivers with depression: initial findings," Rehabilitation Psychology, vol. 57, no. 2, pp. 124-139, 2012.

[11] N. Chi and G. Demiris, "A systematic review of telehealth tools and interventions to support family caregivers," Journal of Telemedicine and Telecare, vol. 21, no. 1, pp. 37-44, 2015.

[12] AHRQ, “ePSS," 2019, https://epss.ahrq.gov/PDA/index.jsp/.

[13] A. Au, D. Gallagher-Thompson, M. Wong et al., "Behavioral activation for dementia caregivers: scheduling pleasant events and enhancing communications," Clinical Interventions in Aging, vol. 10, pp. 611-619, 2015.

[14] T. Bakas, C. J. Farran, J. K. Austin, B. A. Given, E. A. Johnson, and L. S. Williams, "Stroke caregiver outcomes from the telephone assessment and skill-building kit (TASK)," Topics in Stroke Rehabilitation, vol. 16, no. 2, pp. 105-121, 2009.
[15] T. Bakas, J. K. Austin, B. Habermann et al., “Telephone assessment and skill-building kit for stroke caregivers: a randomized controlled clinical trial," Stroke, vol. 46, no. 12, pp. 3478-3487, 2015.

[16] L. C. Campbell, F. J. Keefe, C. Scipio et al., "Facilitating research participation and improving quality of life for African American prostate cancer survivors and their intimate partners," Cancer, vol. 109, no. S2, pp. 414-424, 2007.

[17] J. Chodosh, B. A. Colaiaco, K. I. Connor et al., "Dementia care management in an underserved community: the comparative effectiveness of two different approaches," Journal of Aging and Health, vol. 27, no. 5, pp. 864-893, 2015.

[18] L. L. Davis, L. D. Burgio, K. C. Buckwalter, and M. Weaver, "A comparison of in-home and telephone-based skill training interventions with caregivers of persons with dementia," Journal of Mental Health and Aging, vol. 10, pp. 31-44, 2004.

[19] G. Demiris, D. Parker Oliver, E. Wittenberg-Lyles et al., "A noninferiority trial of a problem-solving intervention for hospice caregivers: in person versus videophone," Journal of Palliative Medicine, vol. 15, no. 6, pp. 653-660, 2012.

[20] J. N. Dionne-Odom, A. Azuero, K. D. Lyons et al., "Family caregiver depressive symptom and grief outcomes from the ENABLE III randomized controlled trial," Journal of Pain and Symptom Management, vol. 52, no. 3, pp. 378-385, 2016.

[21] S. Clancy Dollinger and K. Chwalisz, "Reaching rural caregivers with a multicomponent telehealth intervention: the telehelp line for caregivers," Professional Psychology: Research and Practice, vol. 42, no. 6, pp. 528-534, 2011.

[22] T. R. Elliott, D. Brossart, J. W. Berry, and P. R. Fine, "Problemsolving training via videoconferencing for family caregivers of persons with spinal cord injuries: a randomized controlled trial," Behaviour Research and Therapy, vol. 46, no. 11, pp. 1220-1229, 2008.

[23] T. R. Elliott and J. W. Berry, "Brief problem-solving training for family caregivers of persons with recent-onset spinal cord injuries: a randomized controlled trial," Journal of Clinical Psychology, vol. 65, no. 4, pp. 406-422, 2009.

[24] C. J. Farran, D. W. Gilley, J. J. McCann, J. L. Bienias, D. A. Lindeman, and D. A. Evans, "Psychosocial interventions to reduce depressive symptoms of dementia caregivers: a randomized clinical trial comparing two approaches," Journal of Mental Health and Aging, vol. 10, pp. 337-350, 2004.

[25] C. Farran, O. Paun, F. Cothran et al., "Impact of an individualized physical activity intervention on improving mental health outcomes in family caregivers of persons with dementia: a randomized controlled trial," AIMS Medical Science, vol. 3, no. 1, pp. 15-31, 2015.

[26] S. Finkel, S. J. Czaja, Z. Martinovich, C. Harris, D. Pezzuto, and R. Schulz, "E-Care: a telecommunications technology intervention for family caregivers of dementia patients," The American Journal of Geriatric Psychiatry, vol. 15, no. 5, pp. 443-448, 2007.

[27] J. R. Gant, A. M. Steffen, and S. A. Lauderdale, "Comparative outcomes of two distance-based interventions for male caregivers of family members with dementia," American Journal of Alzheimer's Disease and Other Dementias, vol. 22, no. 2, pp. 120-128, 2007.

[28] J. S. Grant, T. R. Elliott, M. Weaver, A. A. Bartolucci, and J. N. Giger, "Telephone intervention with family caregivers of stroke survivors after rehabilitation," Stroke, vol. 33, no. 8, pp. 2060-2065, 2002. 
[29] R. J. Hartke and R. B. King, "Telephone group intervention for older stroke caregivers," Topics in Stroke Rehabilitation, vol. 9, no. 4, pp. 65-81, 2003.

[30] X. Hu, M. A. Dolansky, Y. Su, X. Hu, M. Qu, and L. Zhou, "Effect of a multidisciplinary supportive program for family caregivers of patients with heart failure on caregiver burden, quality of life, and depression: a randomized controlled study," International Journal of Nursing Studies, vol. 62, pp. 11-21, 2016.

[31] L. Keeping-Burke, M. Purden, N. Frasure-Smith, S. Cossette, F. McCarthy, and R. Amsel, "Bridging the transition from hospital to home: effects of the VITAL telehealth program on recovery for CABG surgery patients and their caregivers," Research in Nursing \& Health, vol. 36, no. 6, pp. 540-553, 2013.

[32] A. C. King, K. Baumann, P. O'Sullivan, S. Wilcox, and C. Castro, "Effects of moderate-intensity exercise on physiological, behavioral, and emotional responses to family caregiving: a randomized controlled trial," The Journals of Gerontology. Series A, Biological Sciences and Medical Sciences, vol. 57, no. 1, pp. M26-M36, 2002.

[33] T. Kwok, B. Wong, I. Ip, K. Chui, D. Young, and F. Ho, “Telephone-delivered psychoeducational intervention for Hong Kong Chinese dementia caregivers: a single-blinded randomized controlled trial," Clinical Interventions in Aging, vol. 8, pp. 1191-1197, 2013.

[34] J. H. Lingler, S. M. Sereika, C. M. Amspaugh et al., “An intervention to maximize medication management by caregivers of persons with memory loss: intervention overview and twomonth outcomes," Geriatric Nursing, vol. 37, no. 3, pp. 186191, 2016.

[35] T. V. McCann, W. Songprakun, and J. Stephenson, "A randomized controlled trial of guided self-help for improving the experience of caring for carers of clients with depression," Journal of Advanced Nursing, vol. 71, no. 7, pp. 1600-1610, 2015.

[36] L. S. Porter, F. J. Keefe, J. Garst et al., "Caregiver-assisted coping skills training for lung cancer: results of a randomized clinical trial," Journal of Pain and Symptom Management, vol. 41, no. 1, pp. 1-13, 2011.

[37] P. A. Rivera, T. R. Elliott, J. W. Berry, and J. S. Grant, "Problem-solving training for family caregivers of persons with traumatic brain injuries: a randomized controlled trial," Archives of Physical Medicine and Rehabilitation, vol. 89, no. 5, pp. 931-941, 2008.

[38] J. M. Shaw, J. M. Young, P. N. Butow et al., "Improving psychosocial outcomes for caregivers of people with poor prognosis gastrointestinal cancers: a randomized controlled trial (Family Connect)," Supportive Care in Cancer, vol. 24, no. 2, pp. 585-595, 2016.

[39] T. L. Smith and R. W. Toseland, "The effectiveness of a telephone support program for caregivers of frail older adults," The Gerontologist, vol. 46, no. 5, pp. 620-629, 2006.

[40] J. A. Tanner, B. S. Black, D. Johnston et al., “A randomized controlled trial of a community-based dementia care coordination intervention: effects of MIND at Home on caregiver outcomes," The American Journal of Geriatric Psychiatry, vol. 23, no. 4, pp. 391-402, 2015.

[41] G. Tremont, J. Duncan Davis, D. S. Bishop, and R. H. Fortinsky, "Telephone-delivered psychosocial intervention reduces burden in dementia caregivers," Dementia, vol. 7, no. 4 , pp. 503-520, 2008.
[42] G. Tremont, J. D. Davis, G. D. Papandonatos et al., "Psychosocial telephone intervention for dementia caregivers: a randomized controlled trial," Alzheimer's \& Dementia, vol. 11, no. 5, pp. 541-548, 2015.

[43] G. Wilz, D. Schinköthe, and R. Soellner, "Goal attainment and treatment compliance in a cognitive-behavioral telephone intervention for family caregivers of persons with dementia," GeroPsych, vol. 24, no. 3, pp. 115-125, 2011.

[44] G. Wilz and R. Soellner, "Evaluation of a short-term telephone-based cognitive behavioral intervention for dementia family caregivers," Clinical Gerontologist, vol. 39, no. 1, pp. 25-47, 2016.

[45] L. Winter and L. N. Gitlin, "Evaluation of a telephone-based support group intervention for female caregivers of community-dwelling individuals with dementia," American Journal of Alzheimer's Disease and Other Dementias, vol. 21, no. 6, pp. 391-397, 2007.

[46] N. Beauchamp, A. B. Irvine, J. Seeley, and B. Johnson, "Worksite-based Internet multimedia program for family caregivers of persons with dementia," The Gerontologist, vol. 45, no. 6, pp. 793-801, 2005.

[47] M. M. Blom, S. H. Zarit, R. B. M. Groot Zwaaftink, P. Cuijpers, and A. M. Pot, "Effectiveness of an Internet intervention for family caregivers of people with dementia: results of a randomized controlled trial," PLoS One, vol. 10, no. 2, article e0116622, 2015.

[48] M. Chih, L. L. DuBenske, R. P. Hawkins et al., "Communicating advanced cancer patients' symptoms via the Internet: a pooled analysis of two randomized trials examining caregiver preparedness, physical burden, and negative mood," Palliative Medicine, vol. 27, no. 6, pp. 533-543, 2013.

[49] B. Hattink, F. Meiland, H. van der Roest et al., "Web-based STAR E-Learning course increases empathy and understanding in dementia caregivers: results from a randomized controlled trial in the Netherlands and the United Kingdom," Journal of Medical Internet Research, vol. 17, no. 10, article e241, 2015.

[50] B. Kajiyama, L. W. Thompson, T. Eto-Iwase et al., "Exploring the effectiveness of an Internet-based program for reducing caregiver distress using the iCare Stress Management eTraining Program," Aging \& Mental Health, vol. 17, no. 5, pp. 544-554, 2013.

[51] P. Klemm, E. Hayes, C. Diefenbeck, and B. Milcarek, "Online support for employed informal caregivers," Computers, Informatics, Nursing, vol. 32, no. 1, pp. 10-20, 2014.

[52] E. Marziali and P. Donahue, "Caring for others: Internet video-conferencing group intervention for family caregivers of older adults with neurodegenerative disease," The Gerontologist, vol. 46, no. 3, pp. 398-403, 2006.

[53] C. L. Petranovich, S. L. Wade, H. G. Taylor et al., "Long-term caregiver mental health outcomes following a predominately online intervention for adolescents with complicated mild to severe traumatic brain injury," Journal of Pediatric Psychology, vol. 40, no. 7, pp. 680-688, 2015.

[54] L. L. Pierce, V. L. Steiner, S. A. Khuder, A. L. Govoni, and L. J. Horn, "The effect of a web-based stroke intervention on carers' well-being and survivors' use of healthcare services," Disability and Rehabilitation, vol. 31, no. 20, pp. 1676-1684, 2009.

[55] S. P. Raj, T. N. Antonini, K. S. Oberjohn, A. Cassedy, K. L. Makoroff, and S. L. Wade, "Web-based parenting skills program for pediatric traumatic brain injury reduces 
psychological distress among lower-income parents," The Journal of Head Trauma Rehabilitation, vol. 30, no. 5, pp. 347-356, 2015.

[56] G. C. Smith, N. Egbert, M. Dellman-Jenkins, K. Nanna, and P. A. Palmieri, "Reducing depression in stroke survivors and their informal caregivers: a randomized clinical trial of a web-based intervention," Rehabilitation Psychology, vol. 57, no. 3, pp. 196-206, 2012.

[57] A. Vander Stoep, C. A. McCarty, C. Zhou, C. M. Rockhill, E. N. Schoenfelder, and K. Myers, "The children's attention-deficit hyperactivity disorder telemental health treatment study: caregiver outcomes," Journal of Abnormal Child Psychology, vol. 45, no. 1, pp. 27-43, 2017.

[58] S. L. Wade, J. Carey, and C. R. Wolfe, "An online family intervention to reduce parental distress following pediatric brain injury," Journal of Consulting and Clinical Psychology, vol. 74, no. 3, pp. 445-454, 2006.

[59] S. L. Wade, N. C. Walz, J. Carey et al., "A randomized trial of teen online problem solving: efficacy in improving caregiver outcomes after brain injury," Health Psychology, vol. 31, no. 6, pp. 767-776, 2012.

[60] C. Eisdorfer, S. J. Czaja, D. A. Loewenstein et al., "The effect of a family therapy and technology-based intervention on caregiver depression," The Gerontologist, vol. 43, no. 4, pp. 521531, 2003.

[61] M. Grover, U. Naumann, L. Mohammad-Dar et al., "A randomized controlled trial of an Internet-based cognitivebehavioural skills package for carers of people with anorexia nervosa," Psychological Medicine, vol. 41, no. 12, pp. 25812591, 2011.

[62] B. L. Hicken, C. Daniel, M. Luptak, M. Grant, S. Kilian, and R. W. Rupper, "Supporting caregivers of rural veterans electronically (SCORE)," The Journal of Rural Health, vol. 33, no. 3, pp. 305-313, 2017.

[63] D. F. Mahoney, B. J. Tarlow, and R. N. Jones, "Effects of an automated telephone support system on caregiver burden and anxiety: findings from the REACH for TLC intervention study," The Gerontologist, vol. 43, no. 4, pp. 556-567, 2003.

[64] D. Parker Oliver, G. Demiris, K. Washington, R. L. Kruse, and G. Petroski, "Hospice family caregiver involvement in care plan meetings: a mixed-methods randomized controlled trial," The American Journal of Hospice \& Palliative Care, vol. 34, no. 9, pp. 849-859, 2017.

[65] J. D. Piette, D. Striplin, N. Marinec, J. Chen, and J. E. Aikens, "A randomized trial of mobile health support for heart failure patients and their informal caregivers," Medical Care, vol. 53, no. 8, pp. 692-699, 2015.

[66] J. M. Powell, R. Fraser, J. A. Brockway, N. Temkin, and K. R. Bell, "A telehealth approach to caregiver self-management following traumatic brain injury," The Journal of Head Trauma Rehabilitation, vol. 31, no. 3, pp. 180-190, 2016.

[67] J. L. Steel, D. A. Geller, K. H. Kim et al., "Web-based collaborative care intervention to manage cancer-related symptoms in the palliative care setting," Cancer, vol. 122, no. 8, pp. 1270-1282, 2016.

[68] A. M. Steffen and J. R. Gant, "A telehealth behavioral coaching intervention for neurocognitive disorder family carers," International Journal of Geriatric Psychiatry, vol. 31, no. 2, pp. 195203, 2016.
[69] V. P. Williams, L. Bishop-Fitzpatrick, J. D. Lane et al., "Videobased coping skills to reduce health risk and improve psychological and physical well-being in Alzheimer's disease family caregivers," Psychosomatic Medicine, vol. 72, no. 9, pp. 897904, 2010.

[70] R. L. Glueckauf and J. S. Loomis, “Alzheimer's caregiver support online: lessons learned, initial findings and future directions," NeuroRehabilitation, vol. 18, no. 2, pp. 135-146, 2003. 